\title{
Pilot-scale electro-kinetic remediation of lead polluted field sediments: model designation, numerical simulation, and feasibility evaluation
}

Xinyu Mao ${ }^{1,2^{*}}$ (D) Xiaohou Shao ${ }^{1,2}$ and Zhanyu Zhang ${ }^{1,2}$

\begin{abstract}
Background: The accumulation of lead (Pb) in sediments from anthropogenic activities possesses serious threats to ecosystem and human health. Recycling of sediments for agricultural plantation is politically encouraged while their applications are still limited due to the high cost and poor environmental compatibility of existing remediation techniques. Electro-kinetic remediation (EKR) enhanced with electrode polarity inversion (EPI) strategy was an effective technique for $\mathrm{Pb}$ decontamination from low permeable matrix. However, lacking full understanding of the interactions between $\mathrm{Pb}$ and sediment constituents restricts the wide application of this technology.

Results: In this study, an innovative approach based on model simulation and feasibility analysis was proposed for guiding the pilot-scale remediation and recycling of $\mathrm{Pb}$-polluted sediments. Initially, a specific two-dimensional (2D) model that consisted of transport-reactive modules was designed, with assumptions of operating parameters and reaction equations. A three-step sequential non-iterative split-operator computation scheme was implemented to simulate the electrochemical variables of EKR. The predicted results indicated that the electrode reversal should be conducted around $48 \mathrm{~h}$ to avoid $\mathrm{pH}$ polarization and $\mathrm{Pb}$ precipitation. In addition, $12 \mathrm{~h}$ was suggested to be the preferable EPI duration as the shortest time required $(226 \mathrm{~h}$ ) to remove the target level of sediment Pb. Afterwards, a comparative study was performed between the experimental and simulated data to validate the model accuracy. Good agreements were achieved in spite of minor discrepancies which suggested the designed model could approximately predict the performance of EPI-enhanced EKR. Finally, the feasibility analysis was conducted based on a parametric study. In consideration of energy utilization efficiency, concentration of $220 \mathrm{mg} / \mathrm{kg}$ was determined as the lower limit of safety threshold for $\mathrm{Pb}$ removal. In this level, the maximum energy consumption (EC), materials, electrolyte posttreatment, and labor expenditure for sediments remediation were $110 \$ / \mathrm{m}^{3}, 450 \$ /$ remediation unit, $2 \$ / \mathrm{L}$, and $300 \$ /$ remediation unit, respectively, and the agricultural eco-environment was safe during the recycling process.
\end{abstract}

Conclusion: We believed that the methodology and results in this study could be employed as an useful tool to support the designation of full-scale EKR and the reutilization of contaminated sediments.

Keywords: Pb-polluted sediments, Pilot-scale decontamination, Electro-kinetic remediation, Electrode polarity inversion, Numerical modeling, Ecology risk evaluation

\footnotetext{
*Correspondence: mxy880731@163.com

${ }^{1}$ College of Agricultural Engineering, Hohai University, Nanjing 210098,

China

Full list of author information is available at the end of the article
} 


\section{Background}

For navigational purpose, periodical dredging of estuarine and coastal sediments is often necessary. Generally, sediments are soil particles in the bottom of the aquatic environment. They are natural sinks of organic matter $(\mathrm{OM})$, carbonates, sulfides, iron oxides, as well as toxic metals. Lead $(\mathrm{Pb})$ is the most common toxic metal accumulated in the sediments due to the industrial and agricultural activities [1-4]. As reported, the concentration of $\mathrm{Pb}$ in the top layer of the sediments may be as high as $600 \mathrm{mg} / \mathrm{kg}$, which may possess a great risk to human health and ecosystem safety during its dredging and disposal [5]. Currently, recycling of sediments for agricultural plantation is politically encouraged in consideration of cost-saving. However, their applications are still limited due to the shortages of existing remediation techniques such as requirement of a large space, high cost, low sustainability, and poor environmental compatibility [6-8]. Therefore, development of cost-effective and ecofriendly technology for the recovery of metal-polluted sediments becomes an urgent issue.

The electro-kinetic remediation (EKR) is widely accepted as an effective approach for removing toxic metals from a matrix with low permeable, high salinity, and strong buffering capacity. This technique involves introduction of a direct low-intensity electric field to mobilize the target pollutants through transport mechanisms such as electromigration, electroosmosis, and electrophoresis [9]. Induced by electric field, other complex effects like water electrolysis occur at the surface of the electrodes, which respectively generates the $\mathrm{H}^{+}$and $\mathrm{OH}^{-}$ions at the anode and cathode. These ions are transported towards the oppositely charged electrode which causes acidification and alkalization in treated sediments, respectively. Alkalization effect can result in species precipitation and pores blockage, thus impeding the transport of toxic metals. Electrode polarity inversion (EPI) is the most frequently adopted strategy to prevent this negative effect by exchanging the direction of electric field in certain patterns. It is beneficial for neutralizing the $\mathrm{OH}^{-}$ions around the initial cathode areas and releasing the immobilized toxic metals from the solid particles [10].

Many studies proved that the EPI-enhanced EKR (EPIEKR) is able to deal with a wide range of toxic metals (e.g., $\mathrm{Pb}, \mathrm{Cd}, \mathrm{Cu}, \mathrm{Cr}, \mathrm{Zn}$, and $\mathrm{Ni}$ ) [11-16]. However, most of these studies focused on the metal-spiked samples at a laboratory scale, the full-scale remediation of fieldcontaminated sediments was rarely reported. Lacking full understanding of the transport processes and chemical equilibriums of toxic metals is the main limiting factor to widespread usage of this technique in practical applications. As reported, the decontamination efficiency of EPI-EKR is highly dependent on the interactions between contaminants and sediment substances in pore solution [17]. This shows the importance of choosing preferable operating parameters, which can hardly be estimated through the empirical approach due to the strong nonlinearity occurring during the remediation processes [18]. For instance, our previous study determined the optimal timing and duration of EPI which were two significant parameters for improving the removal of toxic metals in the porous matrix [19]. These lab-based parameters are case-specific, while directly introducing them to field-scale applications may lead to the inaccuracy of achievable results. Thus, determination of such operating parameters is usually case by case and may be time-consuming.

In order to thoroughly comprehend the complicated mechanisms and efficiently design the appropriate schemes for a full-scale treatment, modeling becomes an essential tool to deal with the technique issues. Many mathematical models were proposed for the simulation of metal extraction with EKR [20-26]. Most of them coupled with the Nernst-Planck or Poisson equation with finite element method to describe both transportations and reactions taking place during the EKR [27]. Despite the considerable efforts were made on model development, poor agreements existed in comparison of predicted and experimental data. On one hand, the geochemical reactions such as precipitation-dissolution, oxidation-reduction, and adsorption-desorption between the species and matrix constituents were not accurately simulated [26]. They are indeed key factors for precise modeling and the limited case studies and data in literatures were the main reasons for the inaccurate simulations [28]. On the other hand, several important intrinsic parameters (e.g., matrix buffering capacity, electrical conductivity, species diffusion coefficients, etc.) could not be straightforwardly hypothesized based on the preliminary data and often were arbitrarily set due to the lack of suitable numerical packages for model parameter assumptions. As a result, model discrepancies derived from the above-mentioned problems affected the performance and optimization of a full-scale EKR.

Although the detailed investigations were carried out towards EPI-EKR, its feasibility to treat field metal-polluted sediments was not assessed yet. One of the major issues to be considered is cost, which is significantly correlated to energy consumption (EC). Unlike soils, sediments with a large presence of $\mathrm{OM}$ and carbonates are usually characterized by a high sorption and a buffering capacity. These characteristics may lead to an undesirable energy loss during the remediation. Moreover, energy loss also occurs when electric current passes through the electric wires and electrodes, which are regarded as the additional resistances of EKR system. In many 
cases, particular focuses were not given to discriminate between energy losses and energy used effectively for remediation. Thus, cost minimization by improving the conductivity of sediments and selecting the proper materials for electric components was often neglected.

Considering the recycling of sediments for agricultural plantation, evaluation of the relevant ecological risks caused by toxic metals is another important issue for feasibility analysis. At present, Nemerow index, enrichment factor, geoaccumulation index, and potential ecological risk index are common methods for the assessment of soil metal pollution [29-32]. However, some of these methods were not originally developed for such a purpose and the parameters and formulas included may not accurately calculate the contamination index of soil system. In addition, the analysis of metal pollution in agricultural products is not contained in current work, which significantly influences the scientific reliability of evaluation consequences.

To overcome the above-mentioned limitations, a model-based approach was proposed for the full-scale treatment and recycling of $\mathrm{Pb}$-polluted sediments with EPI-EKR. The work included the designation and numerical implementation of a two-dimensional (2D) reactive-transport model with the software of COMSOL Multiphysics ${ }^{\circledR}$ and PHREEQC. The model fully described the transport mechanisms as well as geochemical reactions of $\mathrm{Pb}$ in sediments. Particular focus was given to the assumptions of model parameters for better construction of the real contaminated sediment environment. The timing and duration of EPI were optimized based on the simulation results of $\mathrm{pH}$ profiles, $\mathrm{Pb}$ mobilizations and distributions, and $\mathrm{Pb}$ removal efficiencies. The accuracies of the predicted results were then validated through comparing with the experimental data of the pilot-scale EKR tests. Subsequently, a parametric study was performed to analyze the EC of EKR with optimal operating parameters. Minimization of the remediation cost was conducted based on the energy utilization efficiencies and control standards of $\mathrm{Pb}$ concentration in sediments and soils. Finally, an innovative method was applied to estimate the ecology risks in agricultural soils and products induced by the recycling of treated sediments. The developed methodology and achieved results in this study may be regarded as a guidance for the costeffective decontamination and eco-friendly recycling of metal-polluted sediments.

\section{Methods}

\section{Sediment sampling and characterization}

The sediment samples were collected from the top layer $(10-30 \mathrm{~cm})$ of Liqing harbor $\left(32^{\circ} 23^{\prime} \mathrm{N}, 118^{\circ} 80^{\prime} \mathrm{E}\right)$, which is located close to the industrial estate of Luhe district in Nanjing city, Jiangsu Province, China (Fig. 1). The dredged sediments were kept in cool conditions $\left(-20^{\circ} \mathrm{C}\right)$ and stored in airtight plastic barrels during transport. Pretreatment of homogenization including dewatering, air-drying $(72 \mathrm{~h})$, and sieving (2-mm sieve) were conducted before the experiments. Sediment physico-chemical properties and relevant analytical methods were summarized in Table 1. All the analytical procedures were applied in triplicate. Major elements and heavy metal(loid)s were extracted after acid digestion and the contents in solution were determined with inductively coupled plasma mass spectrometry (ICP-MS). As a target pollutant, the speciation of $\mathrm{Pb}$ in investigated sediments was analyzed through BCR sequential extraction method and the total $\mathrm{Pb}$ was about $346 \mathrm{mg} / \mathrm{kg}$.

\section{Layout of the treatment system}

The diagram of the pilot-scale EKR plant was schematically presented Fig. 2a. It consisted of rectangular basin $(\mathrm{L} \times \mathrm{W} \times \mathrm{H}=12 \mathrm{~m} \times 10 \mathrm{~m} \times 4 \mathrm{~m})$ to contain a volume of $360 \mathrm{~m}^{3}$ polluted sediments. The basin was divided into eight equivalent remediation units (Fig. 2b) with twelve electrode wells inserted for the installation of electrodes. The arrays of the electrode wells were equidistantly distributed and the unit distance in the vertical and horizontal direction was about $2.7 \mathrm{~m}$ and $4.7 \mathrm{~m}$, respectively. The electrode wells were connected to the electrolyte management system by PVC pipes for electrolyte circulation. Graphite electrode rods $(\mathrm{L} \times \Phi=360 \mathrm{~cm} \times 20 \mathrm{~cm})$ were applied as both anode and cathode and connected to a DC power supplier at a constant voltage potential of $0.5 \mathrm{~V} / \mathrm{cm}$. The dredged sediments in the basin were treated in a unit-by-unit order as shown in Fig. 2b. A sensor-based monitoring system was used to record the variations of sediment $\mathrm{pH}$ and passing electric currents. The replaced electrolyte $(0.1 \mathrm{M} \mathrm{KCl})$ and generated noxious gas $\left(\mathrm{Cl}_{2}\right)$ were, respectively, transferred to the electrolyte purification and gas scrubbing systems for post-treatment.

\section{Model designation Initialization}

Some operating parameters were initially assumed for model implementation. The major migrating species considered in the polluted sediments were $\mathrm{H}^{+}, \mathrm{OH}^{-}, \mathrm{K}^{+}, \mathrm{Cl}^{-}$, $\mathrm{Pb}^{2+}, \mathrm{PbCl}^{+}, \mathrm{PbCl}_{3}{ }^{-}, \mathrm{PbCl}_{4}^{2-}$, and $\mathrm{PbCl}_{2}$. These species hold significant contents at working conditions and around $13 \%$ of the total $\mathrm{Pb}$ was considered $\mathrm{as}^{2+}$ based on the speciation analysis. The same diffusion coefficient was assigned to $\mathrm{Pb}^{2+}$ and its aqueous complexes according to the literature [33]. Before transport, reactions of precipitation and dissolution were hypothesized to occur between the soluble and solid phases of sediment $\mathrm{Pb}$. The solid phases taken into 

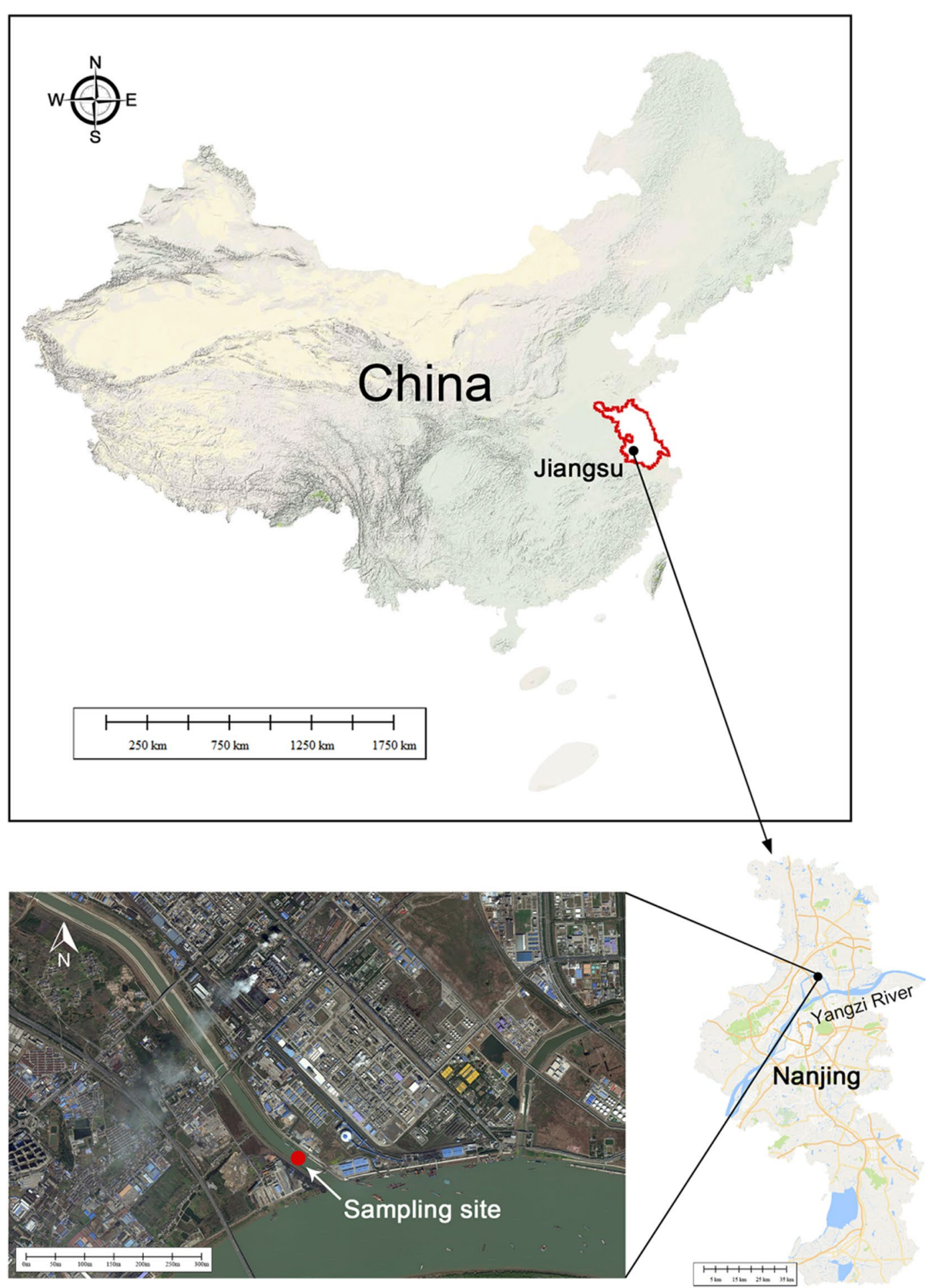

Fig. 1 Sampling site map of Liqing harbor in Luhe district of Nanjing city, Jiangsu Province, China

account in the model included $\mathrm{Pb}_{3}(\mathrm{OH})_{2}\left(\mathrm{CO}_{3}\right)_{2}, \mathrm{~Pb}(\mathrm{OH})_{2}$, and $\mathrm{PbCO}_{3}$. The equilibrium constants for the precipitation and dissolution of $\mathrm{Pb}$ were referred to the thermodynamic database of PHREEQC [34].
In addition, some other conditions were also assumed in order to simplify the model. The electric potential that distributed along the vertical direction was neglected, reflecting in the presentation of the actual 3D geometric 
Table 1 Physico-chemical properties, major elements, and heavy metal(loid)s of the experimental sediments

\begin{tabular}{|c|c|c|c|}
\hline Properties & Methods & Unit & Value \\
\hline \multicolumn{4}{|l|}{ Grain size distribution } \\
\hline $\mathrm{d}>2 \mathrm{~mm}$ & ASTM D 421 & $\%$ & 0 \\
\hline $0.063 \mathrm{~mm}<\mathrm{d} \leq 2 \mathrm{~mm}$ & & & $54.2 \pm 2.7$ \\
\hline $\mathrm{d} \leq 0.063 \mathrm{~mm}$ & & & $45.8 \pm 3.8$ \\
\hline Porosity & ASTM D 854 & $\%$ & $46.2 \pm 4.5$ \\
\hline $\mathrm{pH}$ & US-EPA $9045 d$ & & $6.8 \pm 0.44$ \\
\hline \multicolumn{4}{|l|}{ Buffering capacity } \\
\hline to $\mathrm{pH}-2.0 \pm 0.2$ & ASTM D4972 & $\mathrm{mol} \mathrm{H}^{+} / \mathrm{kg}$ & 21.24 \\
\hline to $\mathrm{pH}-13.0 \pm 0.2$ & & $\mathrm{~mol} \mathrm{OH}^{-} / \mathrm{kg}$ & 0.96 \\
\hline Water content & ASTM D 2980 & $\%$ & $31.4 \pm 2.2$ \\
\hline Electrical resistivity & ASTM D 5682 & $\Omega m$ & $0.75 \pm 0.13$ \\
\hline Electrical conductivity & ASTM D5298 & $\mathrm{mS} / \mathrm{cm}$ & $13.4 \pm 1.6$ \\
\hline CEC & US-EPA 9081 & $\mathrm{cmol} / \mathrm{kg}$ & $124.6 \pm 8.3$ \\
\hline Sulfur & US-EPA 9031 & $\%$ & $0.32 \pm 0.02$ \\
\hline Nitrogen & US-EPA 351.2 & $\%$ & $0.56 \pm 0.04$ \\
\hline $\mathrm{OM}$ & ASTM D 2974 & $\%$ & $12.3 \pm 1.2$ \\
\hline DOM & ASTM D7573 & $\mathrm{mg} / \mathrm{kg}$ & $16.5 \pm 1.7$ \\
\hline Carbonate & ASTM D 4373 & $\%$ & $26.4 \pm 4.3$ \\
\hline Total carbon & ASTM D 5997 & $\%$ & $6.2 \pm 0.93$ \\
\hline \multicolumn{4}{|l|}{ Metals/salts } \\
\hline $\mathrm{Ca}$ & US-EPA 6020 & $\mathrm{mg} / \mathrm{kg}$ & $6840 \pm 560$ \\
\hline $\mathrm{Fe}$ & & & $8800 \pm 420$ \\
\hline Al & & & $7260 \pm 340$ \\
\hline $\mathrm{Mg}$ & & & $5050 \pm 410$ \\
\hline $\mathrm{Mn}$ & & & $105.6 \pm 8.2$ \\
\hline K & & & $2520 \pm 340$ \\
\hline $\mathrm{Na}$ & & & $6380 \pm 460$ \\
\hline P & & & $1540 \pm 120$ \\
\hline \multicolumn{4}{|l|}{ Heavy metal(loid)s } \\
\hline $\mathrm{Cu}$ & US-EPA 6020 & $\mathrm{mg} / \mathrm{kg}$ & $83.7 \pm 5.3$ \\
\hline $\mathrm{Zn}$ & & & $43.8 \pm 3.2$ \\
\hline $\mathrm{Cd}$ & & & $0.8 \pm 0.1$ \\
\hline As & & & $15.4 \pm 1.8$ \\
\hline $\mathrm{Ni}$ & & & $16.2 \pm 2.1$ \\
\hline $\mathrm{Cr}$ & & & $26.7 \pm 4.6$ \\
\hline \multicolumn{4}{|l|}{$\mathrm{Pb}$} \\
\hline $\mathrm{EXT}^{\mathrm{a}}$ & & & $44.8 \pm 4.2$ \\
\hline OXID ${ }^{b}$ & & & $98.8 \pm 8.7$ \\
\hline $\mathrm{RED}^{c}$ & & & $176 \pm 12.4$ \\
\hline $\mathrm{RES}^{\mathrm{d}}$ & & & $25.7 \pm 4.8$ \\
\hline
\end{tabular}

a Acid extractable fraction

${ }^{b}$ Oxidizable fraction

c Reducible fraction

d Residual fraction

remediation setup with a $2 \mathrm{D}$ model. The advective flow and electrophoresis that contributed to $\mathrm{Pb}$ transport were not considered due to the low hydraulic permeability of the experimental sediments. The pore geometry of the sediments was assumed to be isotropic with fixed porosity and tortuosity during the remediation. Moreover, the sediment water content was regarded to be constant with a saturation degree of $100 \%$ due to continuous complement of the electrolyte.

\section{Governing equations}

Two coupled modules that described the transport processes and chemical equilibriums made up the model. In transport module, the ionic species were assumed to migrate through electromigration and electroosmosis under electric force. Their flux densities $J_{i}\left(\mathrm{~mol} / \mathrm{m}^{2} \mathrm{~s}\right)$ passing through the cross-sectional area of the sediments were described as

$$
J_{i}=-D_{i}^{*} \nabla c_{i}-U_{i}^{*} c_{i} \nabla \phi-k_{e o} c_{i} \nabla \phi,
$$

where $i$ represents the species, $D_{i}^{*}\left(\mathrm{~m}^{2} / \mathrm{s}\right)$ and $C_{i}(\mathrm{~mol} /$ $\mathrm{m}^{3}$ ) are, respectively, the effective diffusion coefficient and content of $i$ th specie, $\phi(\mathrm{V})$ denotes the voltage, $U_{i}^{*}\left(\mathrm{~m}^{2} / \mathrm{V} \mathrm{s}\right)$ is the effective ionic mobility coefficient, and $k e o\left(\mathrm{~m}^{2} / \mathrm{V} \mathrm{s}\right)$ is the electroosmosis permeability coefficient.

The transport of ionic species was further expressed by Nernst-Planck equation in consideration of mass conservation:

$$
n \frac{\partial c i}{\partial t}=-\nabla \times\left[-D_{i}^{*} \nabla c i-\left(U_{i}^{*}+k e o\right) c i \nabla \phi\right]+n G i,
$$

where $n$ is the porosity of sediments, $t(\mathrm{~s})$ is the elapsed time, and $G_{i}\left(\mathrm{~mol} / \mathrm{m}^{3} \mathrm{~s}\right)$ is the generated volume of $i$ th specie via chemical reactions. Since the pathway for ion migration in porous medium is tortuous, the effects of sediment porosity $(n)$ and tortuosity $(\tau)$ were taken into account to define the $D_{i}^{*}$ and $U_{i}^{*}$ in Eq. (2) as

$$
D_{i}^{*}=n \tau D_{i}, \quad U_{i}^{*}=n \tau U_{i} .
$$

The porosity was predetermined in Table 1 and the tortuosity was assumed to span in a range of $0.01-0.84$ depending on the physico-chemical properties of the sediments [35]. The relationship between $D_{i}^{*}$ and $U_{i}^{*}$ could be defined by Einstein-Nernst relation as a single property:

$$
U_{i}^{*}=\frac{D_{i}^{*} Z_{i} F}{R T},
$$

where $R(8.314 \mathrm{~J} / \mathrm{K} \mathrm{mol})$ and $F(96,485 \mathrm{C} / \mathrm{mol})$ are the ideal gas constant and Faraday's constant, respectively, $Z_{i}$ is the ionic charge of $i$ th specie, and $T(\mathrm{~K})$ is the absolute temperature.

According to Helmholtz and Smoluchowski's theory, the keo in Eqs. (1) and (2) is an integrated function of porosity $n$, liquid dielectric constant $\varepsilon(F / m)$, zeta 

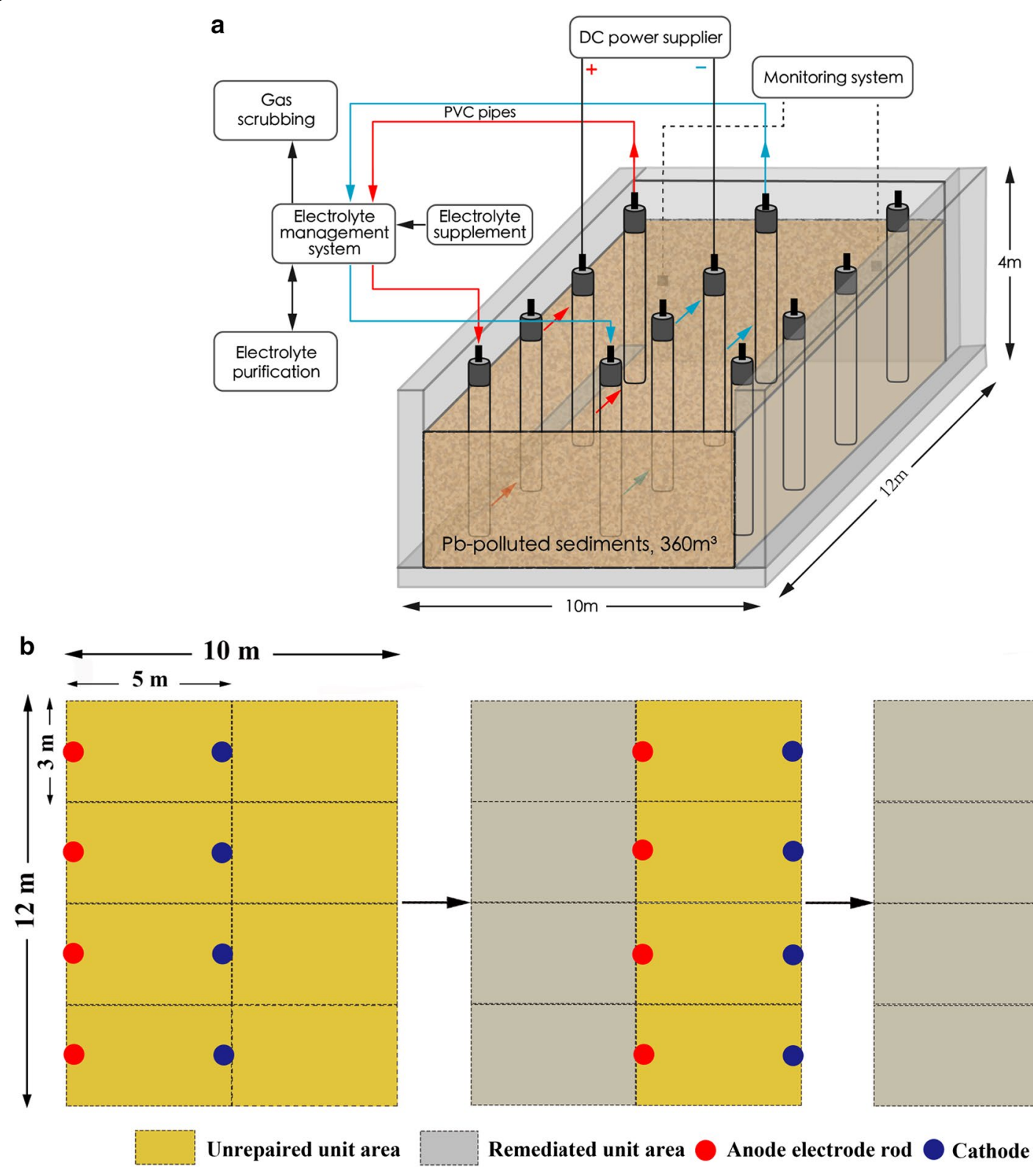

Fig. 2 a Schematic diagram of the pilot-scale EKR plant and $\mathbf{b}$ remediation process of the dredged sediments

potential $\zeta(\mathrm{V})$, and fluid viscosity $\eta\left(\mathrm{N} \mathrm{s} / \mathrm{m}^{2}\right)$ of the porous matrix [36]:

$$
k_{e o}=n \frac{\varepsilon \zeta}{\eta} .
$$

In this equation, the values of porosity and liquid dielectric constant were listed in Table 1 , and the viscosity of the electrolyte $(0.1 \mathrm{M} \mathrm{KCl})$ was about 1.12 -fold compared to that of water referred to Qiu's report [37]. As a result, the zeta potential becomes the determining factor and can be calculated through the expression of volume-averaged EOF $Q_{e o}\left(\mathrm{~m}^{3} / \mathrm{s}\right)$ :

$$
Q_{e o}=n A \frac{D \zeta}{\eta} E_{z}
$$

where $A\left(\mathrm{~cm}^{2}\right)$ and $E_{z}(\mathrm{~V} / \mathrm{cm})$ are, respectively, the crosssectional area and the electric potential intensity.

In chemical module, the reactions which possess great contributions to sediment decontamination were described via a set of non-linear algebraic equations. 
Water electrolysis is one of the main reactions which has electrochemical oxidation and reduction at the surface of electrodes:

$$
\begin{aligned}
& 2 \mathrm{H}_{2} \mathrm{O} \rightarrow \mathrm{O}_{2} \uparrow+4 \mathrm{H}^{+}+4 e^{-} \text {(Anode) } \\
& 2 \mathrm{H}_{2} \mathrm{O}+2 e^{-} \rightarrow \mathrm{H}_{2} \uparrow+2 \mathrm{OH}^{-} \text {(Cathode). }
\end{aligned}
$$

The presence of $\mathrm{Cl}^{-}$ions due to the application of $\mathrm{KCl}$ electrolyte resulted in the generation of $\mathrm{Cl}_{2}$ gas under the same redox potential of water oxidation. However, this effect was neglected in the model since the concentration of added $\mathrm{Cl}^{-}$was low, which might not be competitive with water oxidation.

The surface complexation is another main reaction that describes the acid buffering capacity of the experimental matrix. It is related to the ion exchange between the generated $\mathrm{H}^{+}$and adsorbed metals on the active sites of the solid particles:

$$
\equiv S O H+H^{+} \rightleftarrows \equiv S O H_{2}^{+} ; \equiv S O H \rightleftarrows \equiv S O^{-}+H^{+},
$$

where $\equiv S O H$ represents the active sites of the solid particles and $S$ represents the adsorbed metals. Due to the double-layer structure, the above protonation and deprotonation reactions are mainly dependent on sediment $\mathrm{pH}$ without considering electrostatic attraction or repulsion. The reactions were further simulated by a nonelectrostatic model to calculate the relevant equilibrium constants:

$$
K_{1}=\frac{\left[\equiv S O H_{2}^{+}\right]}{[\equiv S O H]\left[H^{+}\right]} ; \quad K_{2}=\frac{\left[\equiv S O^{-}\right]\left[H^{+}\right]}{[\equiv S O H]} .
$$

The adsorption and desorption of $\mathrm{Pb}$ onto sediment particle surfaces were also modeled by using an adsorption isotherm:

$$
S_{P b}^{a}=K_{d} c_{P b},
$$

where $S_{P b}^{a}(\mathrm{~mol} / \mathrm{mg})$ denotes the concentration of $\mathrm{Pb}$ adsorbed on sediment particles, $K_{d}\left(\mathrm{~m}^{3} / \mathrm{kg}\right)$ denotes the linear distribution coefficient of liquid and solid phases, and $c_{P b}\left(\mathrm{~mol} / \mathrm{m}^{3}\right)$ denotes the content of $\mathrm{Pb}$ in pore liquid.

\section{Numerical implementation, simulation, and calibration}

A three-step sequential non-iterative split-operator scheme was implemented to compute the aforementioned transport and chemical processes (Fig. 3). In the first step, some assumptions were made for model initialization. Then, the transport behaviors of dissolved chemical species under a constant voltage were simulated by using the finite element method with COMSOL Multiphysics ${ }^{\circledR}$. In this step, the chemical phenomena that act as driving factors of the EKR were calculated by PhreeqcRM. Subsequently, the above two steps were integrated with the coupling time arbitrarily set to $5 \times 10^{4} \mathrm{~s}$ [35]. During the calculation loop, the approach of operator splitting was applied to compute the reactive-transport equilibriums, which minimized the

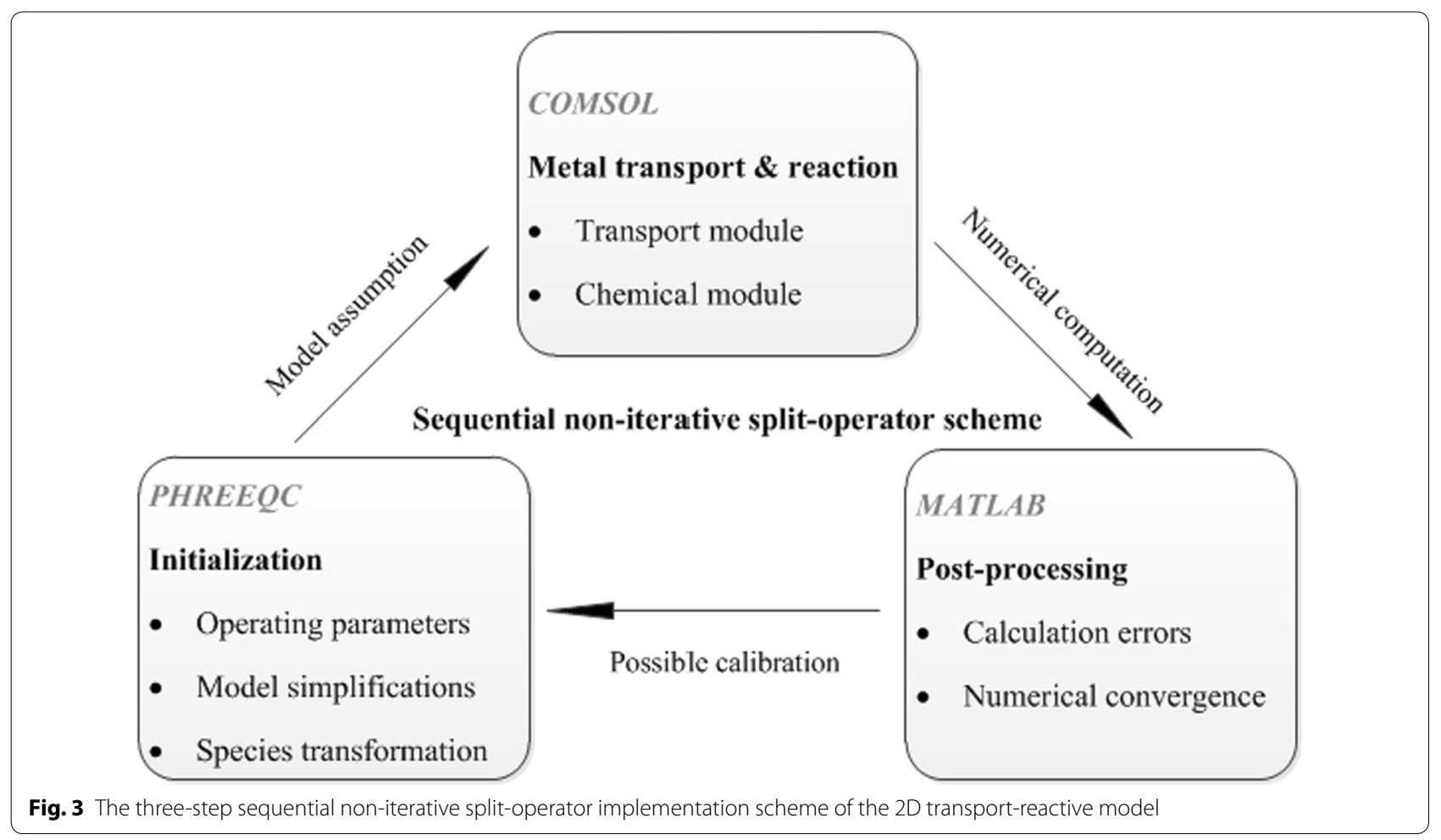


calculation errors and ensured an acceptable computation time. In the last step, numerical convergence was achieved and used for data analysis in post-processing. Possible calibrations could be made according to error adjustments by COMSOL in combination with model validations by comparing the predicted data with the full-scale experimental results.

\section{Energy consumption and cost analysis}

The EC for Pb electromigration, voltage drops, and management of EKR system was independently calculated. A specific concept of energy utilization efficiency $(\beta)$ was defined to describe the relationship between EC and metal removal:

$$
\beta=\frac{\eta}{W_{i}}
$$

where $\eta(\mathrm{mg})$ is the removal mass of sediment $\mathrm{Pb}$ and $W_{i}$ $(\mathrm{kWh})$ is the relevant EC.

The cost of EC for EKR to remove the target level of sediment $\mathrm{Pb}$ was estimated. The minimization of such a cost was conducted based on the energy utilization efficiencies and the safety control standards for sediment $\mathrm{Pb}$.

\section{Ecology risk evaluation}

Field plantation experiments were conducted to evaluate the ecology risks induced by the recycling of treated sediments. An innovative approach which comprehensively estimated the qualities of both soils and vegetables was applied. The evaluation method considered the factors of metal valance, environmental standard for soils, background values of soil metals, soil loading capacity of pollution, and food safety control standard for the contaminant, which ensured the scientific reliability of the evaluation results. Vegetables of Brassica juncea, Brassica pekinensis, and Spinacia oleracea $L$. were chosen for plantation due to their good accumulating ability on soil $\mathrm{Pb}$. They could efficiently accumulate the $\mathrm{Pb}$ in roots and transport them to shoots with satisfying translocation factors [38]. In addition, as hyperaccumulator, the accumulation of $\mathrm{Pb}$ in Brassica juncea should be larger compared to those in Brassica pekinensis and Spinacia oleracea $L$. The $\mathrm{Pb}$ concentration in soils and vegetables was measured with ICP-MS after harvest. All the experiments were conducted in four replicates and the ecological risks were further classified according to the criterions of agro-ecosystem quality assessment.

\section{Results and discussion \\ Numerical simulation results Estimation of EPI timing}

The EPI strategy possessed considerable buffering effects on soil $\mathrm{pH}$ polarization during the EKR process.
It is desirable to alleviate the focusing phenomena such as precipitation of major elements, immobilization of aqueous $\mathrm{Pb}$, and blockage of sediment pores induced by alkalization around the cathode areas. The timing to reverse electrode polarity is important since it directly determines the frequency of EPI and the performance of EKR. For that reason, the appropriate EPI timing was initially evaluated, based on the time-dependent 2D simulations of acidic front and $\mathrm{Pb}$ migration with conventional EKR under pilot-scale conditions (EXP 1).

From the obtained results (Fig. 4), the advances of both acid and basic fronts towards the opposite direction were much faster along the main anode-cathode axis, while became slighter in the same longitudinal positions from the median to the border. This phenomenon could be explained by the electric field distribution that the voltage gradient in the middle axis was higher than at the borders of the remediation unit. As a result, the residual $\mathrm{Pb}$ content followed the same trend that larger transport of $\mathrm{Pb}$ was observed along the central anode-cathode line. The data also showed that intensive $\mathrm{pH}$ polarization occurred at $48 \mathrm{~h}$ and the $\mathrm{pH}$ value close to the anode and the cathode had already polarized to 2.7 and 10.7, respectively. Moreover, a $\mathrm{pH}$ jumping point ( $\mathrm{pH}$ varied from 6 to 9) appeared at that time near the cathode region due to the faster movement of $\mathrm{H}^{+}$[39]. This sharp transition of $\mathrm{pH}$ led to the precipitation of $\mathrm{Pb}$ and an approximately 9.3-19.9\% elevation of $\mathrm{Pb}$ concentration was showed around the $\mathrm{pH}$ jumping section.

The above results demonstrated the fact that the distribution of $\mathrm{Pb}$ highly depended on sediment $\mathrm{pH}$. Without $\mathrm{pH}$ management, $\mathrm{Pb}$ would accumulate in a narrow zone, where stable anionic $\mathrm{Pb}$ complexes and precipitations were formed. This zone corresponded to dead areas where $\mathrm{Pb}^{2+}$ could hardly pass through, especially in the upper and lower corners. Therefore, reversing electrode polarity at the time that intensive $\mathrm{pH}$ polarization appeared was required to promote $\mathrm{Pb}$ removal in these areas. In our study, sediment $\mathrm{pH}$ polarized significantly after $48 \mathrm{~h}$ EKR, which suggested $48 \mathrm{~h}$ might be the preferable timing of EPI. It should be noted that this hypnosis was model specific and may not be generalized. Nevertheless, it could be regarded as valid in cases where similar model designations were assumed.

\section{Evaluation of EPI duration}

The operating duration of EPI is another important parameter that needs to be confirmed as it significantly influences the decontamination efficiency and energy consumption of the EKR system. Theoretically, it should be determined on account of two basic principles that (1) the sediment $\mathrm{pH}$ depolarized to a lightly acidic range which was favorable for the mobilization of $\mathrm{Pb}$ and (2) 


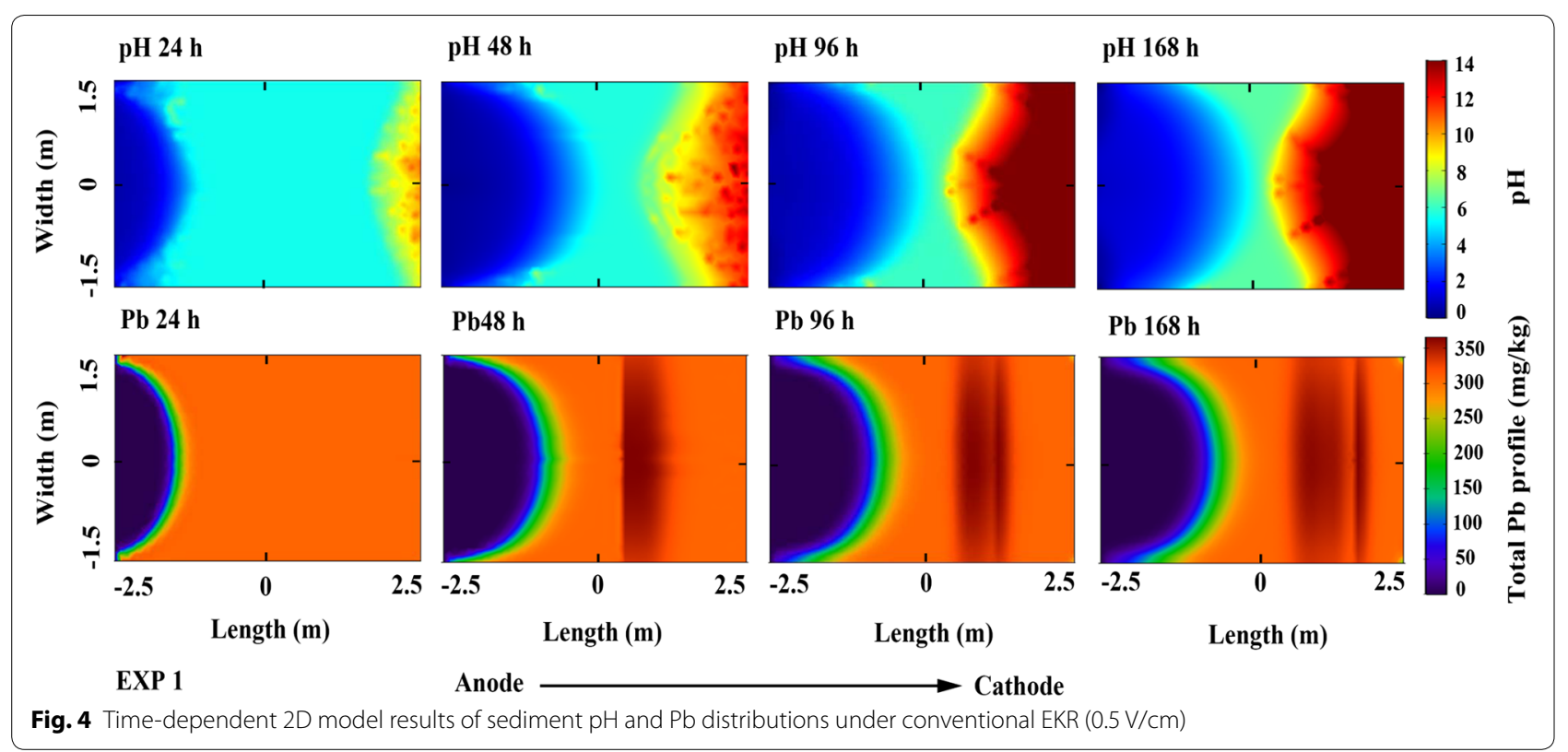

the immobilized $\mathrm{Pb}$ released to the porous matrix without reflux of the aqueous $\mathrm{Pb}$ towards the initial anode regions. In this way, three EPI durations of $6 \mathrm{~h}$ (EXP 2), $12 \mathrm{~h}$ (EXP 3), and 24 h (EXP 4) were assumed for modelbased EKR tests, respectively.

As mentioned, the depolarization effect induced by EPI was the main concern. Thus, indicators of sediment $\mathrm{pH}$ and $\mathrm{Pb}$ distributions in the end of the first three polarity reversions were chosen to describe this effect. From the model results, the sediment pHs were clearly depolarized to different extents as a function of EPI durations (Fig. 5). Regarding to EXP 2, sediment alkalization still existed in 54-h profile and similar patterns were obtained in the following simulations (108 $\mathrm{h}$ and $162 \mathrm{~h}$ ). In terms of EXP 3 and EXP 4, the basification phenomenon close to the initial cathode areas was approximately eliminated and most sediment areas were kept acidic after polarity inversion. Therefore, EPI duration between $12 \mathrm{~h}$ and $24 \mathrm{~h}$ seemed to be proper since desirable environment for $\mathrm{Pb}$ electromigration was established even through slight basification was shown around the initial anode regions of EXP 4.

Referring to the predicted results of $\mathrm{Pb}$ distributions (Fig. 6), the dead zone areas in EXP 2 were diminished after polarity reversion. Moreover, the peak concentration of $\mathrm{Pb}$ moved towards the initial cathode regions with elapsed time. The accumulation of $\mathrm{Pb}$ was totally eliminated in EXP 3 that we suggested all the adsorbed $\mathrm{Pb}$ were released to sediment pore solution. This result may be related to the $\mathrm{pH}$ distribution. Firstly, entire sediment environment was in acidic range resulting in more $\mathrm{Pb}^{2+}$ remobilized from its stable anionic complexes and precipitations via ion exchange [40]. Secondly, due to the acidification effect, more OM in sediments was transformed to dissolved organic matter (DOM) which accelerated the release of immobilized $\mathrm{Pb}$ [41]. According to our pre-measurement, a large part of $\mathrm{Pb}$ in sediments was OM-bounded (oxidizable fraction) since the large amount of OM. Nevertheless, as the increase of DOM, more soluble organic complexing and exchangeable $\mathrm{Pb}$ (acid extractable fraction) could be formed and transported through electromigration and electroosmosis [42]. No obvious backflows of Pb were observed in EXP 2 and EXP 3 during the EPI intervals, while appeared in EXP 4 with a probably $15-25 \%$ of $\mathrm{Pb}$ around the initial cathode areas transported towards the initial anode areas. Thus, based on the aforementioned model results, $12 \mathrm{~h}$ should be the most preferable duration for EPI during the EKR process. This conclusion was further verified through the simulated results of $\mathrm{Pb}$ removals in different EKR tests. Figure 7 illustrated the time required to wipe off the sediment $\mathrm{Pb}$ to a predetermined target level (90\%) and it was ranked as EXP $4=586 \mathrm{~h}>\mathrm{EXP} 2=367 \mathrm{~h}>\mathrm{EXP}$ $3=226 \mathrm{~h}$.

\section{Model validation}

In order to validate the assumption that the designed 2D model could approximately predict the real transportreactive process in practical remediation, comparisons between the predicted and full-scale experimental results were carried out in both conventional and EPI-EKR tests. For that purpose, the electrolyte was collected every $6 \mathrm{~h}$ to measure the $\mathrm{Pb}$ extraction mass and removal rate. Furthermore, the sediment samples were collected along 

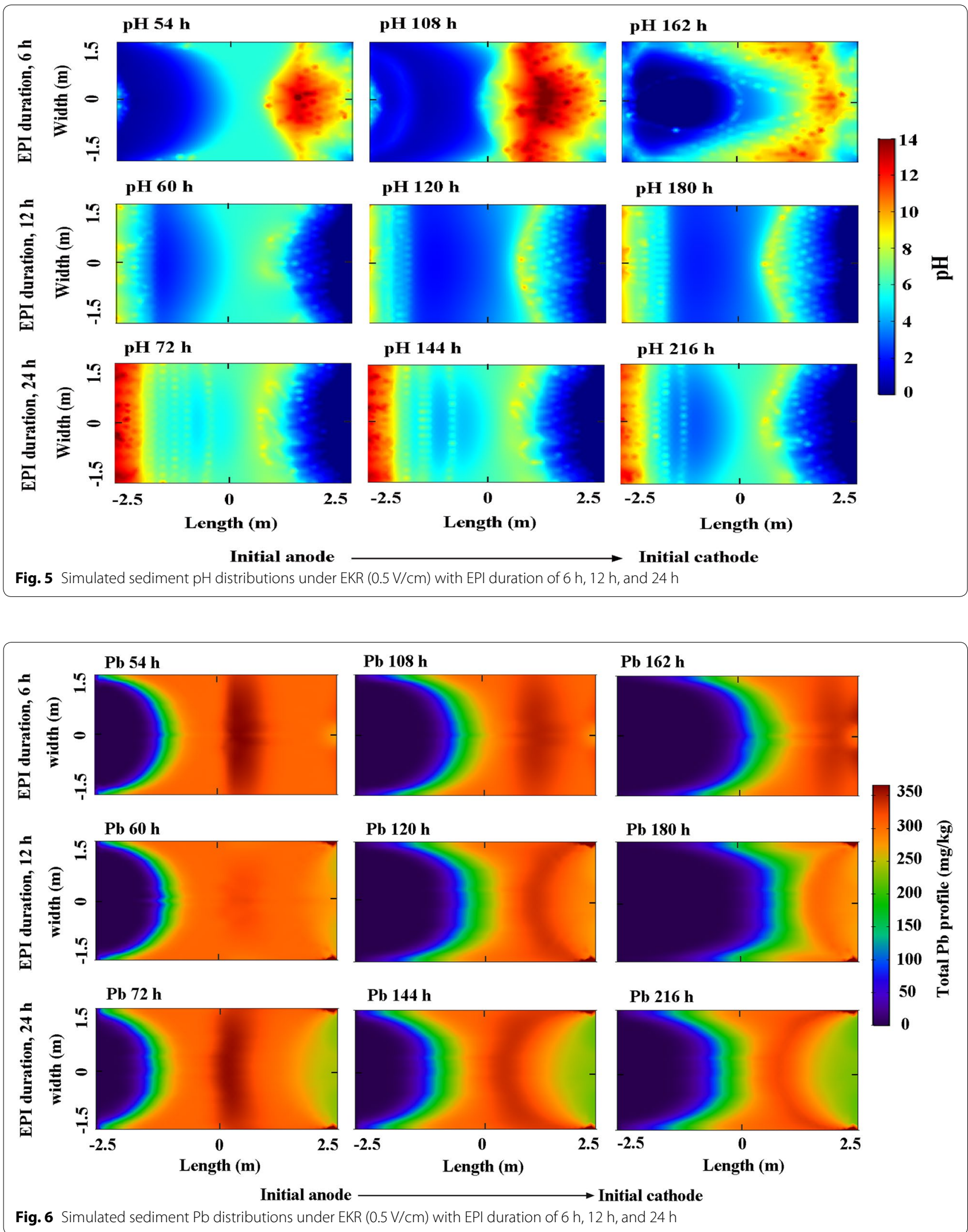

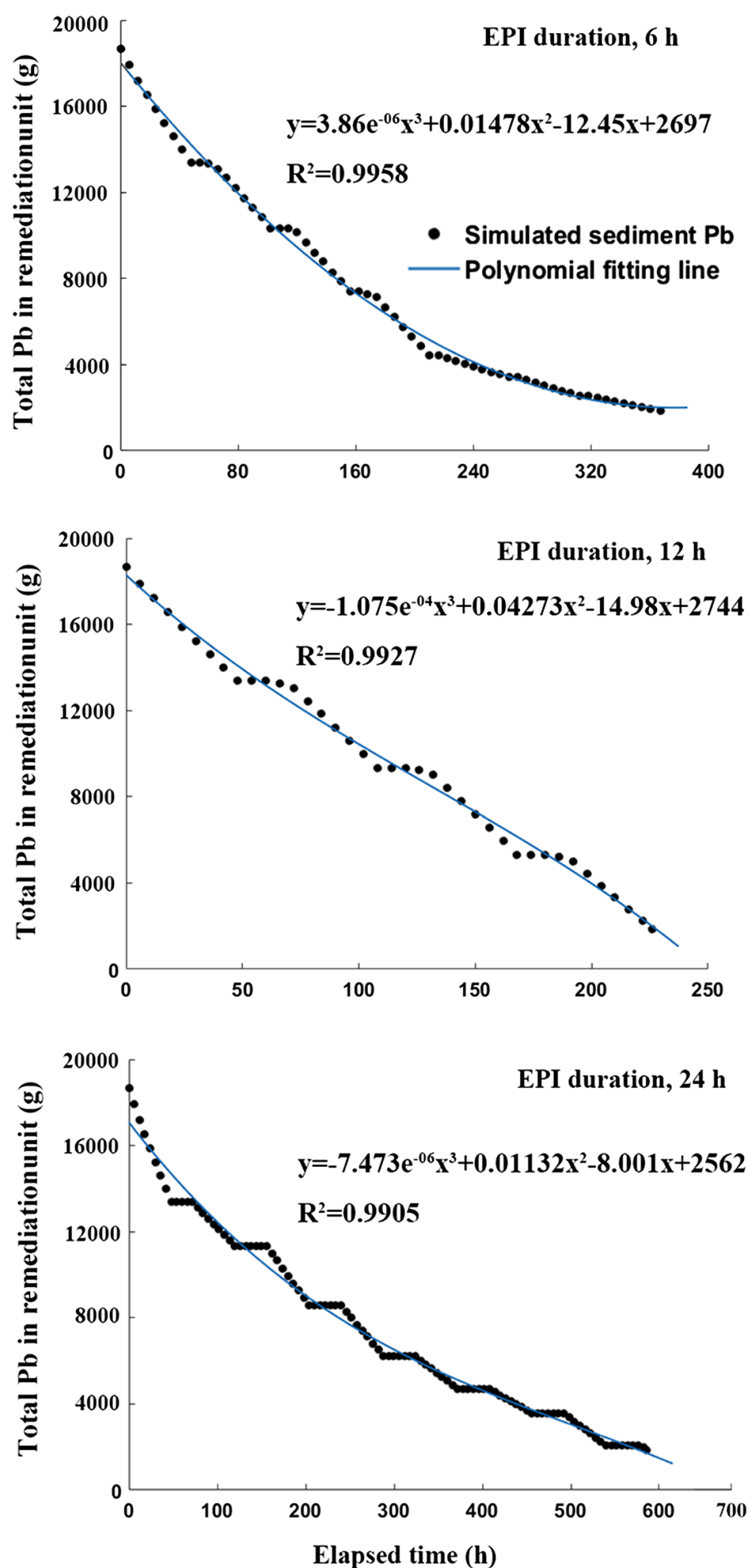

Fig. 7 Simulated Pb removal to a target level of $90 \%$ under EKR $(0.5 \mathrm{~V} / \mathrm{cm})$ with EPI duration of $6 \mathrm{~h}, 12 \mathrm{~h}$, and $24 \mathrm{~h}$ 
the main anode-cathode axis in $48 \mathrm{~h}, 108 \mathrm{~h}, 168 \mathrm{~h}$, and $228 \mathrm{~h}$, respectively, to measure the $\mathrm{pHs}$ and $\mathrm{Pb}$ distributions. All the measurements were conducted in triplicate to ensure the good reproducibility and reliable verification from the acquired data.

The validation of simulated $\mathrm{Pb}$ extraction mass and removal rate were conducted in EXP 1. From the comparisons (Fig. 8), a good agreement was shown between the modeled and measured data in spite of minor discrepancies. In general, the measured data were slightly lower in the early stage while the differences were magnified after the moment of extraction plateau (around $48 \mathrm{~h}$ ). This phenomenon might be caused by the simplification of electric field distribution introduced in the model. In fact, the actual electric strength that contributed to $\mathrm{Pb}$ electromigration was lower than the assumption due to its effect on the outside of the remediation unit was neglected. Moreover, the voltage drops across the electric wires, electrodes, and sediment matrix were also not considered. Consequently, the experimental $\mathrm{Pb}$ extraction mass and removal rate were $5-10 \%$ lower than the predicted results and the errors of actual electric field should lay in this range.

The validation of sediment $\mathrm{pHs}$ and $\mathrm{Pb}$ profiles were carried out in EKR test with optimal EPI duration of $12 \mathrm{~h}$ (EPX 3). Figure 9a presented the $\mathrm{pH}$ profiles prediction and verification. It showed good accuracy even though some minor standard deviations were appeared in the early data ( $48 \mathrm{~h}$ and $108 \mathrm{~h}$ ). These slight disagreements, especially around the anode regions, might result from

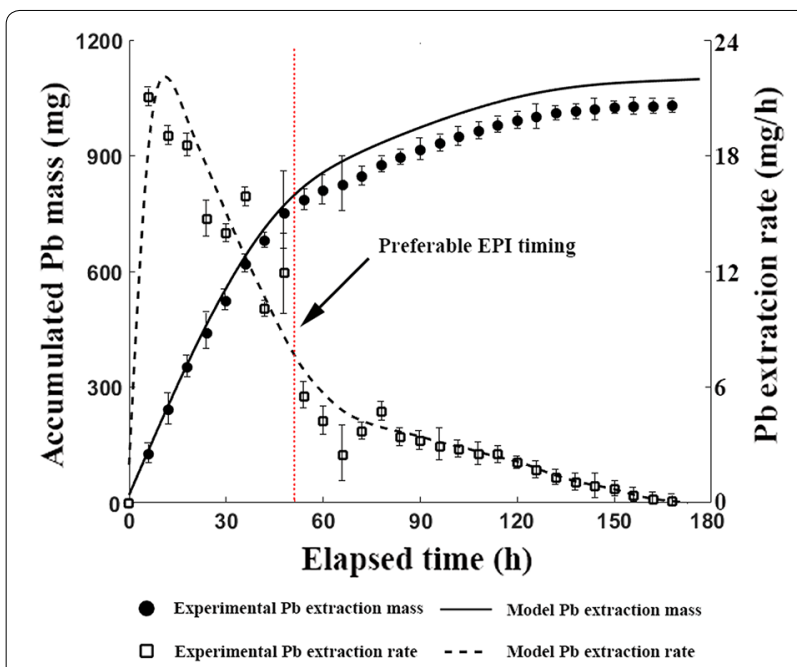

Fig. 8 Comparisons of predicted and measured $\mathrm{Pb}$ extraction mass and removal rate under conventional EKR $(0.5 \mathrm{~V} / \mathrm{cm})$. The preferable $\mathrm{EPI}$ timing referred to the moment that stable anionic $\mathrm{Pb}$ complexes and precipitations were largely formed due to the intensive alkalization effect the integrated effects of transport-reactive reactions and ionic strength variations. As reported, matrix with high buffering capacity would experience a slow kinetic-controlled $\mathrm{pH}$ buffering process during the EKR [43]. This process would particularly influence the short-term $\mathrm{pH}$ distribution. As a result, the mobilization of real acid front in the early stage allocated behind of the results predicted by the model. It should be mentioned that, with continuous depletion of ions in matrix, the ionic strength should be kept decreasing which was assumed as a constant in the model. This effect could slower the movement of acid/basic front in long-term EKR. Nevertheless, excellent agreements were achieved on $\mathrm{pH}$ profiles after $108 \mathrm{~h}$ which enabled to conclude that the impact of electro-reactions on $\mathrm{H}^{+} / \mathrm{OH}^{-}$distributions was significantly larger than that of ionic strength variations. The sediment $\mathrm{Pb}$ profiles with elapsed time were also predicted with a good accuracy (Fig. 9b) except little overestimation of $\mathrm{Pb}$ migration around the initial anode regions. These discrepancies could be due to the stable $\mathrm{Pb}$ bonding fractions in the sediment. Considering the premeasured speciation of $\mathrm{Pb}$ (Table 1), the residual $\mathrm{Pb}$ which accounted for $7.4 \%$ of the total $\mathrm{Pb}$ was of relevant significance. This fraction is less mobile and holds high resilience to acid front. Accordingly, the $\mathrm{Pb}$ content in sediments could not be decreased to zero.

\section{Feasibility analysis}

\section{Energy consumption and cost assessment}

In order to demonstrate the feasibility of the optimal EPI-EKR for sediment $\mathrm{Pb}$ decontamination, a parametric study of EC and relevant cost per remediation unit was performed. The EC taken into account were $\mathrm{EC}$ for $\mathrm{Pb}$ electromigration, voltage drops across the electric wires, graphite electrodes, and sediment matrix, and management of EKR system. They were quantified as a function of applied voltage $(V)$ and current intensity $(I)$ with elapsed time $(t)$. Particularly, the power dissipated outside the remediation zone for $\mathrm{Pb}$ electromigration was neglect. In fact, this energy loss was estimated to be less than $5 \mathrm{~W} / \mathrm{m}^{3}$ according to the model computation. The voltage drops $(\Delta V)$ were simply described as the additional resistances from power source to anode $\left(\Delta V_{A n}\right)$ and from anode to cathode $\left(\Delta V_{C a t}\right)$, respectively:

$$
\Delta V=\Delta V_{A n}+\Delta V_{C a t}=I\left[\sum_{i=1}^{N} \frac{\rho_{i} L_{i}}{S_{i}}\right],
$$

where the electric current $(I)$ was presimulated as a linear transfer function of $I=-0.015 t+13.9, i$ is the component that electric current passing through, $N$ is component's number, and $\rho_{i}(\Omega \mathrm{m}), L_{i}(\mathrm{~m})$, and $S_{i}$ $\left(\mathrm{m}^{2}\right)$ is its resistivity, length, and cross-sectional area, 

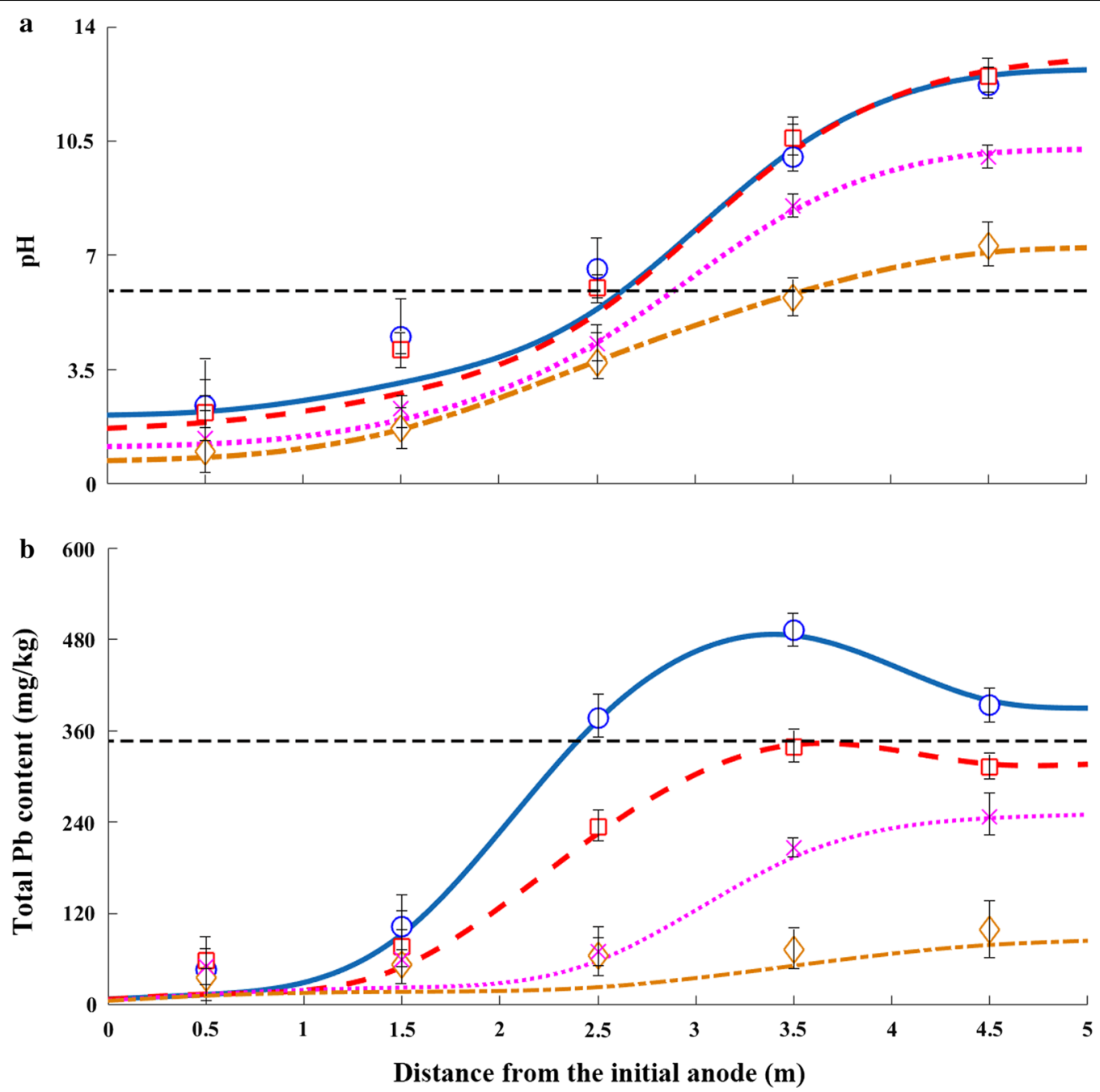

Distance from the initial anode (m)

\section{Initial value $\quad$ Model $48 \mathrm{~h} \quad-\quad$ Model $108 \mathrm{~h}$ \\ Model $168 \mathrm{~h}$ \\ ---- Model $228 \mathrm{~h} \quad \bigcirc$ Experimental $48 \mathrm{~h} \quad \square$ Experimental $108 \mathrm{~h} \quad \times$ Experimental $168 \mathrm{~h}$ \\ Experimental $228 \mathrm{~h}$}

Fig. 9 Validation of simulation: pilot experimental data plotted versus simulated $\mathrm{pH}(\mathbf{a})$ and $\mathrm{Pb}$ distributions (b) alone the median anode-cathode axis under EKR $(0.5 \mathrm{~V} / \mathrm{cm})$ with optimal EPI duration of $12 \mathrm{~h}$

respectively. The management of EKR system mainly included sediment $\mathrm{pH}$ monitoring, electrolyte supplement, and electrolyte circulation. Here, we suggested a total power $(P)$ of $10 \mathrm{~W} / \mathrm{m}^{3}$ to run such managing instruments. A summary of the assumed parameters and relative unit values was shown in Table 2. Subsequently, the assumptions allowed us to calculate the time-dependent $\mathrm{EC}$ with the following relationship:

$$
E C=(V-\Delta V) I t+\Delta V I t+P t .
$$

From this relationship, we were able to discriminate between energy losses and energy used effectively for remediation. Figure 10a showed the results of the referred EC. All the EC had an increasing trend with time and the total energy to remove $90 \%$ of the sediment $\mathrm{Pb}$ was $413 \mathrm{kWh}$. The energy expenditure caused by voltage drops and EKR system management only accounted for around 7-9\% of the total EC, which might imply an approving energy utilization efficiency. For better understanding of the energy utilization 
Table 2 Parameters and unit values of assumed components for energy consumption and cost assessment

\begin{tabular}{|c|c|c|}
\hline Parameter & Value & Unit \\
\hline Applied voltage & 0.5 & $\mathrm{~V} / \mathrm{cm}$ \\
\hline \multicolumn{3}{|l|}{ Sediment } \\
\hline Volume & 45 & $\mathrm{~m}^{3}$ \\
\hline Resistivity & 0.75 & $\Omega m$ \\
\hline \multicolumn{3}{|l|}{ Electric wire } \\
\hline Input length & 15 & $\mathrm{~m}$ \\
\hline Radius & 1 & $\mathrm{~cm}$ \\
\hline Resistivity & 0.018 & $\Omega \mathrm{m}$ \\
\hline \multicolumn{3}{|l|}{ Graphite electrode } \\
\hline Height & 3 & $\mathrm{~m}$ \\
\hline Radius & 10 & $\mathrm{~cm}$ \\
\hline Resistivity & 7.2 & $\Omega m$ \\
\hline \multicolumn{3}{|c|}{ Power for instrument management } \\
\hline pH monitor & 0.05 & $\mathrm{~kW}$ \\
\hline Peristaltic pump & $2 \times 0.2$ & \\
\hline Energy cost & 0.09 & $\$ / \mathrm{kWh}$ \\
\hline
\end{tabular}

efficiency, here we defined it as the energy required to decontaminate $1 \mathrm{mg} \mathrm{Pb}$ in sediments. Obviously, it experienced an exponential decrease with elapsed time due to the continuous depletion of $\mathrm{Pb}^{2+}$ (Fig. 10a). In addition, the energy utilization efficiencies were extremely low during the EPI periods. In this case, a short remediation duration was proposed in order to improve the performance of EPI-EKR.

Same conclusion was achieved when considering the results of cost assessment (Fig. 10b). The cost was strongly dependent on EC and also experienced an exponential growth with continuous remediation. More cost would be required to remove the same amount of $\mathrm{Pb}$ as time passed by. Therefore, it is unnecessary to clean up the $\mathrm{Pb}$ if its concentration in sediments reached the safety threshold as requested. According to the Control Standards of Pollutants in Sludge for Agricultural Use (GB 4284-2018), the maximum content of $\mathrm{Pb}$ is regulated not to exceed $300 \mathrm{mg} / \mathrm{kg}$. Except for this upper limit, a concentration of $220 \mathrm{mg} / \mathrm{kg}$ could be regarded as the lower limit in this case since sharp increase of the cost was observed for further decontamination. In that way, a cost varied from 60 to $110 \$ / \mathrm{m}^{3}$ was assumed for the optimal EPI-EKR to decrease the sediment $\mathrm{Pb}$ to the safety range. It should be noted that the present cost analysis was independently assessed based on the simulated EC results. For estimating the performance of pilot EKR project, other costs included the expenditure for materials (e.g., DC power supplier, multimeter, electrodes, electric wires, pipes, etc.), recycling of $\mathrm{Pb}$ in electrolyte and labor. In our study, this cost was estimated to be $450 \$$ /remediation unit, $2 \$ / \mathrm{L}$ and $300 \$ /$ remediation unit, respectively. Since the materials could be reused and the labor for manufacturing the EKR plant could be neglected in the following treatments, the total cost for implementing such remediation should be acceptable.

\section{Ecology risk evaluation}

Ensuring the ecology safety is an important task for the recycling of metal-polluted sediments for agricultural activities. In the present study, the recycling of sediments with total $\mathrm{Pb}$ content of $345.6 \mathrm{mg} / \mathrm{kg}$ (EXP 5), $300 \mathrm{mg} / \mathrm{kg}$ (EXP 6), and $220 \mathrm{mg} / \mathrm{kg}$ (EXP 7) was respectively implemented for vegetable plantation. The results of detected $\mathrm{Pb}$ concentrations are shown in Table 3. Obviously, more $\mathrm{Pb}$ was found in the soils and vegetables of EXP 5 due to the largest addition of exogenous $\mathrm{Pb}$. In addition, as hyperaccumulator, more $\mathrm{Pb}$ was accumulated in Brassica juncea than in Brassica pekinensis and Spinacia oleracea $L$.

In order to comprehensively estimate the quality of both soils and vegetables influenced by the Pb-polluted sediments, an innovative approach derived from the plant ion impulse and soil relative impact equivalent evaluation method was applied. Initially, the measured $\mathrm{Pb}$ in soil samples $\left(C_{i}\right)$ and agricultural products $\left(C_{A P i}\right)$ were compared with the $\mathrm{Pb}$ standard values for soil quality assessment $\left(C_{s i}\right), \mathrm{Pb}$ background value in soil $\left(C_{B i}\right)$, and $\mathrm{Pb}$ limit values for food safety $\left(C_{L S i}\right)$, respectively. The comparisons were simply expressed as

$$
P_{s s i}=C_{i} / C_{s i} ; \quad P_{S B i}=C_{i} / C_{B i} ; \quad P_{A P i}=C_{A P i} / C_{L S i},
$$

where $C_{B i}$ was premeasured from the sampling site. $C_{s i}$ and $C_{L S i}$ was, respectively, determined as $90 \mathrm{mg} / \mathrm{kg}$ and $0.1 \mathrm{mg} / \mathrm{kg}$ (Table 3) according to the Soil Environmental Quality Risk Control Standard for Soil Contamination of Agricultural Land (GB15618-2018) and the National Food Safety Control Standard for Contaminant (GB27622017). From the obtained data (Table 3), the contents of soil $\mathrm{Pb}$ in different experiments were detected between the $C_{B i}$ and $C_{s i}$ which indicated the reasonable quality of soil analyses. However, significant high $\mathrm{Pb}$ concentration was discovered in vegetables, especially in Brassica juncea, as the increasing of $\mathrm{Pb}$ amount in recycling sediments. Thus, we further defined the values of $X, Y$, and $Z$ to describe the $\mathrm{Pb}$ content. If the specific values of $P_{s s i}$, $P_{S B i}$, and $P_{A P i}$ were larger than 1 , the values of $X, Y$, and $Z$ would be correspondingly set to 1 . Conversely, the values of $X, Y$, and $Z$ would be set to 0 .

Subsequently, based on the above comparisons, we could calculate the parameters of relative impact equivalent (RIE), deviation degree of determination 


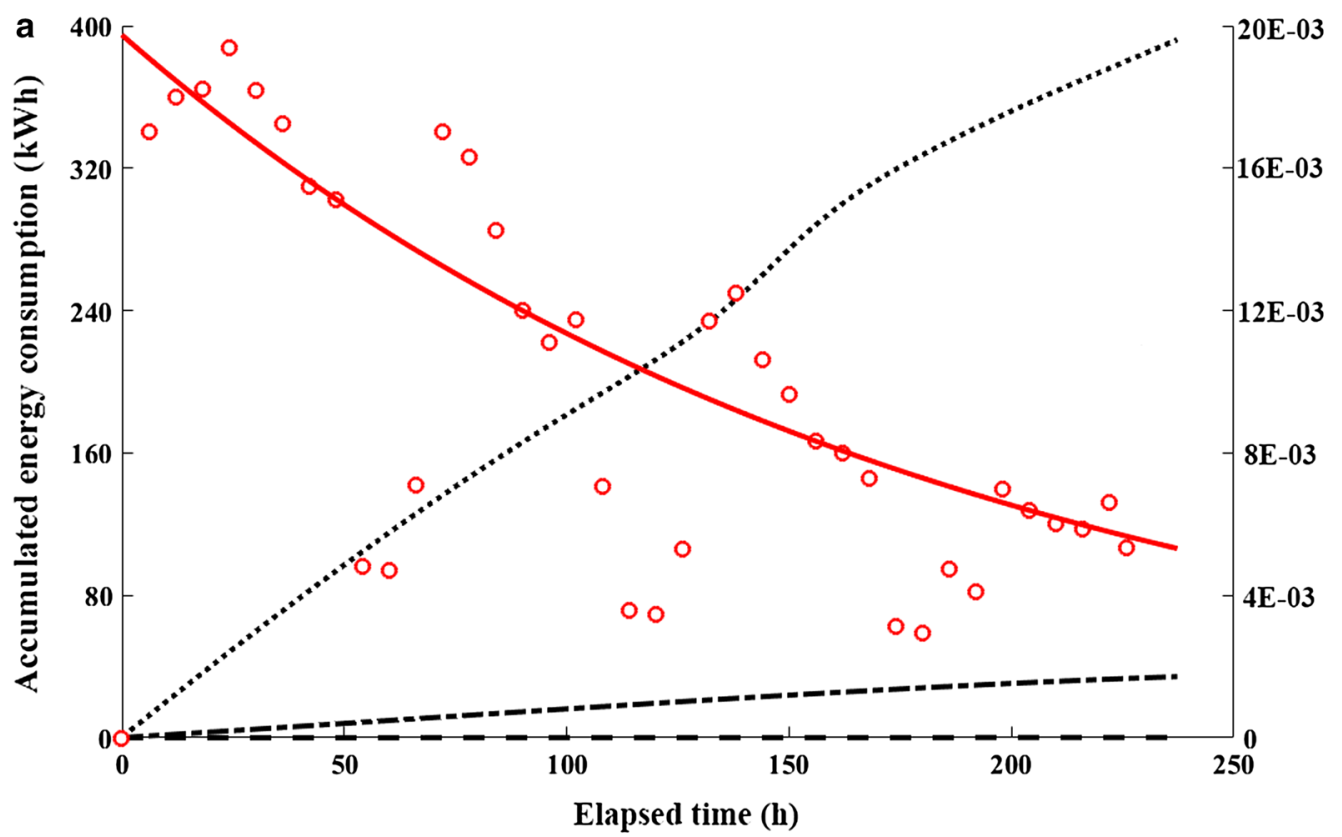

Energy consumption for Pb transport - - Energy consumption for voltage drops

- Energy consumption for system management — Energy consumption for removing $1 \mathrm{mg} \mathrm{Pb}$

○ Exponential fitting line

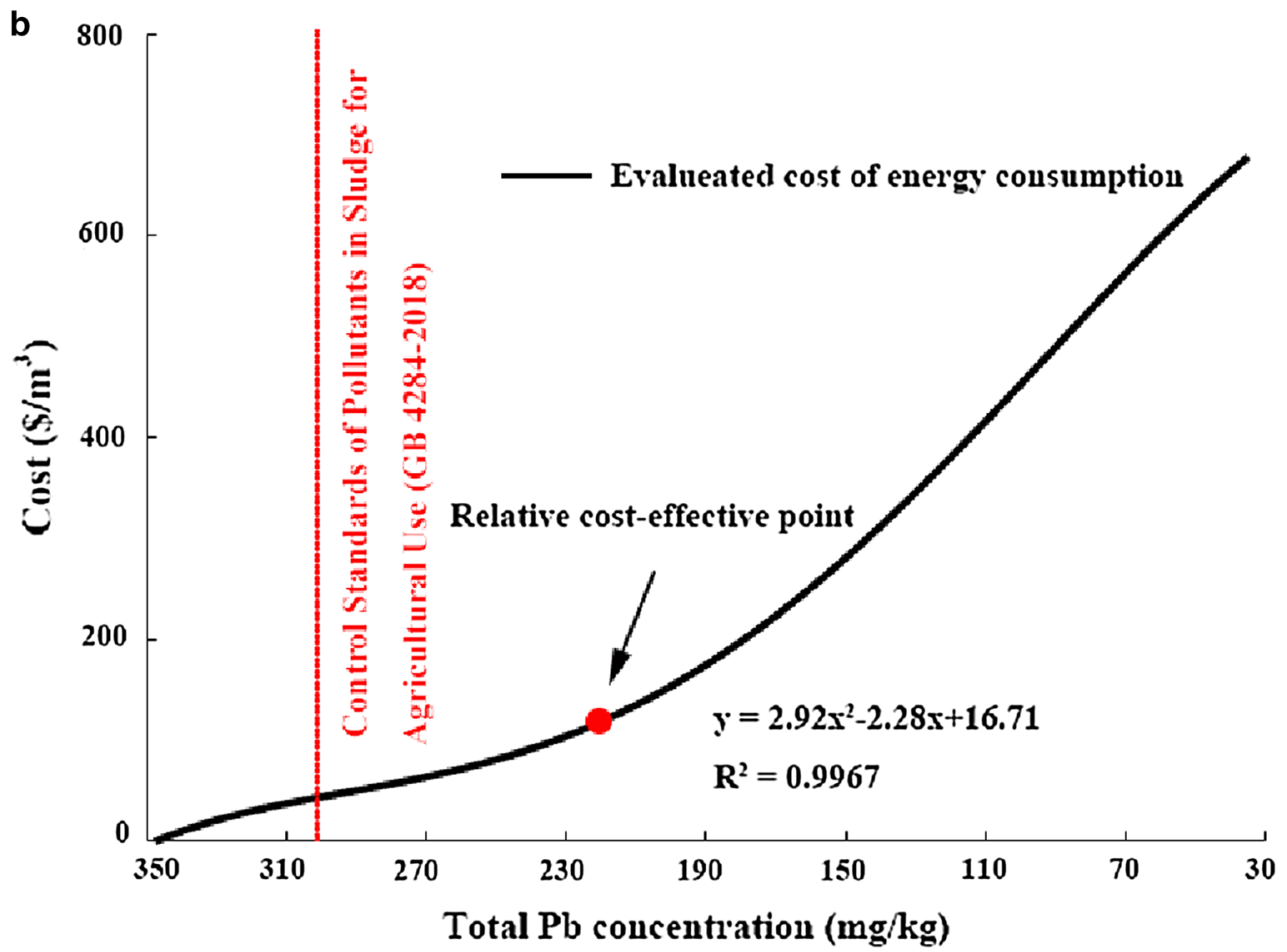

Fig. 10 Energy consumption (a) and cost analysis (b) of the treated unit area under the optimal EPI-EKR $(0.5 \mathrm{~V} / \mathrm{cm}, 12 \mathrm{~h}$ of EPI duration). The relative cost-effective point referred to the moment that sharp increase of the energy cost was required to remove $1 \mathrm{mg} \mathrm{Pb}$ in sediments 
Table 3 Detected $\mathrm{Pb}$ concentrations in soils and vegetables after recycling of sediments with $\mathrm{Pb}$ content of $346 \mathrm{mg} / \mathrm{kg}$, $300 \mathrm{mg} / \mathrm{kg}$, and $220 \mathrm{mg} / \mathrm{kg}$

\begin{tabular}{|c|c|c|c|c|c|}
\hline \multirow[t]{2}{*}{ EXP } & \multirow[t]{2}{*}{ Sample } & \multicolumn{4}{|c|}{$\mathrm{Pb}(\mathrm{mg} / \mathrm{kg})$} \\
\hline & & Soil & Brassica juncea & Brassica pekinensis & $\begin{array}{l}\text { Spinacia } \\
\text { oleracea } L .\end{array}$ \\
\hline \multirow[t]{4}{*}{ Exogenous Pb (346 mg/kg) } & 1 & 46.7 & 0.32 & 0.16 & 0.13 \\
\hline & 2 & 44.1 & 0.37 & 0.20 & 0.16 \\
\hline & 3 & 46.5 & 0.34 & 0.15 & 0.14 \\
\hline & 4 & 45.8 & 0.43 & 0.22 & 0.11 \\
\hline Control standard value $\mathrm{e}^{\mathrm{a}}$ & & 90.0 & 0.10 & 0.10 & 0.10 \\
\hline Background value ${ }^{b}$ & & 18.4 & - & - & - \\
\hline \multirow[t]{4}{*}{ Exogenous Pb (300 mg/kg) } & 5 & 39.2 & 0.27 & 0.13 & 0.06 \\
\hline & 6 & 40.9 & 0.22 & 0.14 & 0.09 \\
\hline & 7 & 38.4 & 0.15 & 0.09 & 0.08 \\
\hline & 8 & 39.6 & 0.18 & 0.16 & 0.07 \\
\hline Control standard value & & 90.0 & 0.10 & 0.10 & 0.10 \\
\hline Background value & & 16.9 & - & - & - \\
\hline \multirow[t]{4}{*}{ Exogenous Pb (220 mg/kg) } & 9 & 25.4 & 0.09 & 0.04 & 0.04 \\
\hline & 10 & 24.3 & 0.08 & 0.06 & 0.02 \\
\hline & 11 & 24.7 & 0.05 & 0.07 & 0.03 \\
\hline & 12 & 23.9 & 0.07 & 0.08 & 0.05 \\
\hline Control standard value & & 90.0 & 0.10 & 0.10 & 0.10 \\
\hline Background value & & 17.8 & - & - & - \\
\hline
\end{tabular}

a Control standard value: the control standard value of Pb content in soils and vegetables requested by the Soil Environmental Quality Risk Control Standard for Soil Contamination of Agricultural Land (GB15618-2018) and the National Food Safety Control Standard for Contaminant (GB2762-2017)

b Background value: the detected $\mathrm{Pb}$ content in soils and vegetables without recycling of $\mathrm{Pb}$-polluted sediments

concentration from the background value $(D D D B)$, and deviation degree of soil standard from the background value $(D D S B)$, respectively, with the following expressions:

$$
\begin{aligned}
& R I E=\left[\sum_{i=1}^{N}\left(P_{s s i}\right)^{1 / n}\right] / N=\left[\sum_{i=1}^{N}\left(C_{i} / C_{s i}\right)^{1 / n}\right] / N \\
& D D D B=\left[\sum_{i=1}^{N}\left(P_{S B i}\right)^{1 / n}\right] / N=\left[\sum_{i=1}^{N}\left(C_{i} / C_{B i}\right)^{1 / n}\right] / N \\
& D D S B=\left[\sum_{i=1}^{N}\left(C_{S i} / C_{B i}\right)^{1 / n}\right],
\end{aligned}
$$

where $N$ was the quantity of the target element and $n$ was the relevant valence of its oxide in soils. Since we only concerned $\mathrm{Pb}$ in this case, the values of $N$ and $n$ were accordingly set to 1 and 2 . The RIE and $D D D B$ were the indexes that reflected the impact of exogenous $\mathrm{Pb}$ on soil quality while $D D S B$ represented the buffering capacity of soil for such pollution. In addition, the quality index of agricultural products $(Q I A P)$ was estimated as follows:

$$
Q I A P=\left[\sum_{i=1}^{N}\left(P_{A P i}\right)^{1 / n}\right] / N=\left[\sum_{i=1}^{N}\left(C_{A P i} / C_{L S i}\right)^{1 / n}\right] / N .
$$

This index indicated the fact that, under a pollution situation, the higher of $\mathrm{Pb}$ concentration was detected in agricultural products, the poorer of product qualities would be.

Afterwards, the influence indexes of comprehensive quality for soils $\left(I I C Q_{S}\right)$ and agricultural products $(I I C$ $Q_{A P}$ ) were calculated by

$$
\begin{aligned}
& I I C Q_{S}=X \bullet(1+R I E)+Y \bullet D D D B / D D S B \\
& I I C Q_{A P}=Z \bullet(1+Q I A P / k)+Q I A P /(k \bullet D D S B),
\end{aligned}
$$

where $k$ is the background correction factor and was set to 5 . Finally, the influence indexes of comprehensive quality for agro-ecosystem (IICQ) were obtained by summing the value of $I I C Q_{S}$ and $I I C Q_{A P}$ :

$$
I I C Q=I I C Q_{S}+I I C Q_{A P} .
$$

Table 4 showed the calculated indexes for the reference cases. The average value of IICQ was clearly increased as the increasing addition of exogenous $\mathrm{Pb}$. Moreover, it 
was observed to be larger in Brassica juncea plantation than those in Brassica pekinensis and Spinacia oleracea L. plantation. This was due to the high ability of Brassica juncea on $\mathrm{Pb}$ accumulation. The IICQ value directly reflected the level of ecological risk which was evaluated with the classification criterions according to the Technical Specification for Soil Environmental Quality Assessment (Table 5). Generally, the agro-ecosystem influenced by the untreated $\mathrm{Pb}$-contaminated sediments (EXP 5) was light polluted with IICQ ranged from 2.06 to 2.28. This

Table 4 Indexes calculations for ecology risk evaluation after recycling of sediments with $\mathrm{Pb}$ content of $346 \mathrm{mg} / \mathrm{kg}$, $300 \mathrm{mg} / \mathrm{kg}$, and $220 \mathrm{mg} / \mathrm{kg}$

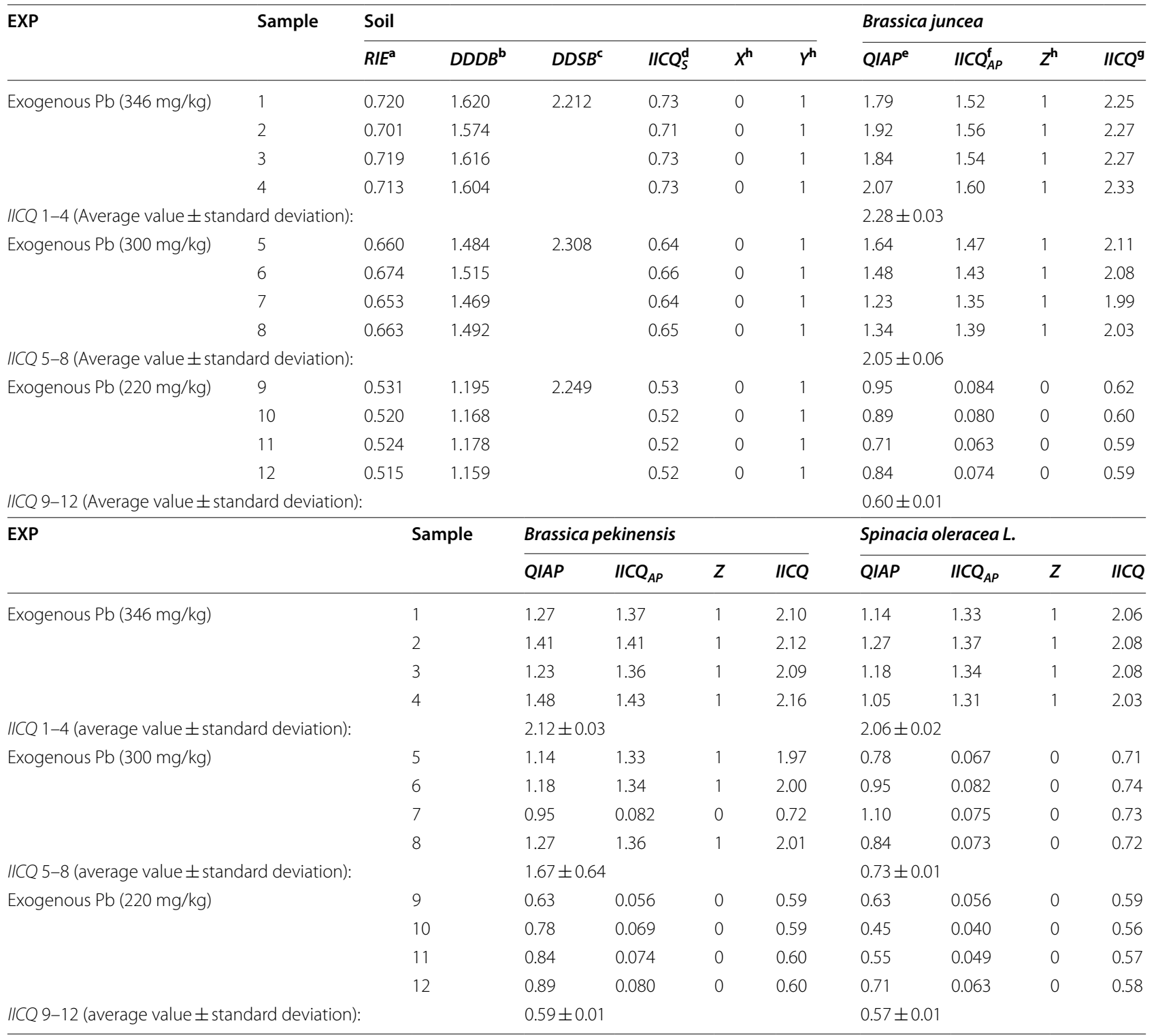

\footnotetext{
${ }^{\text {a }}$ Relative impact equivalent $(R I E)$

b Deviation degree of determination concentration from the background value $(D D D B)$

c Deviation degree of soil standard from the background value (DDSB)

d Influence index of comprehensive quality for soil $\left(I I C Q_{S}\right)$

e Quality index of agricultural product (QIAP)

${ }^{f}$ Influence index of comprehensive quality for agricultural product $\left(I / C Q_{A P}\right)$

$g$ Influence index of comprehensive quality for agro-ecosystem (IICQ)

${ }^{h}$ Defined values for describing the $\mathrm{Pb}$ contents in soils and vegetables $(X, Y, Z)$
} 
pollution was alleviated in EXP 6 where the $\mathrm{Pb}$ content in sediments was decreased to $300 \mathrm{mg} / \mathrm{kg}$ as requested by the safety control standard (GB 4284-2018). However, the ecological risks still existed in the plantation of Brassica juncea and Brassica pekinensis as the obtained IICQ was 2.05 and 1.67, respectively. The agricultural environment seemed safe in EXP 7, where the values of calculated IICQ were far below 1 . This result verified that $220 \mathrm{mg} / \mathrm{kg}$ might be the preferable safety threshold for cost-effective decontamination and eco-friendly recycling of $\mathrm{Pb}$-polluted sediments in the present study.

\section{Conclusions}

In this paper, an innovative methodology which included modeling and feasibility analysis was proposed for pilotscale EPI-EKR to remediate and recycle the $\mathrm{Pb}$-polluted field sediments.

Referring to the modeling of EPI-EKR, the operating parameters of the model were initially assumed containing migrating species, diffusion coefficients, sediment physico-chemical characteristics, etc. They were beneficial for accurately reproducing the field geometry as well as reducing the errors during the modeling. The model consisted of two coupled modules that described the transport processes and chemical equilibriums. A set of equations were assumed to predict the electromigration/ electroosmosis mechanisms and the precipitation/dissolution and adsorption/desorption behaviors of the sediment $\mathrm{Pb}$.

Afterwards, numerical computation was implemented to simulate the time-dependent $\mathrm{pHs}$ and $\mathrm{Pb}$ distributions during the treatment. Under constant electric field, stable anionic $\mathrm{Pb}$ complexes and precipitations were accumulated around the cathode regions from $48 \mathrm{~h}$. This phenomenon was due to the significant sediment alkalization at that time which formed a dead zone to hinder the transport of $\mathrm{Pb}^{2+}$. Thus, $48 \mathrm{~h}$ was suggested to be the proper timing of EPI. Subsequently, the optimization of EPI duration was carried out in consideration of EKR efficiency. Based on the current

Table 5 Classification criterions of agricultural environment quality

\begin{tabular}{ll}
\hline Value of the IICQ & Environment quality state \\
\hline$\| C Q \leq 1$ & Clean (I) \\
$1<\| C Q \leq 2$ & Light polluted (II) \\
$2<\| C Q \leq 3$ & Light polluted (III) \\
$3<\| C Q \leq 5$ & Moderate polluted (IV) \\
$>5$ & Severe polluted (V) \\
\hline
\end{tabular}

a Influence index of comprehensive quality for agro-ecosystem (IICQ): the index for assessing the quality of both soils and agricultural products results, $12 \mathrm{~h}$ seemed to be the preferable EPI period since sediment basification was approximately eliminated and no backflow of aqueous $\mathrm{Pb}$ was observed. Furthermore, the required time for the optimal EPIEKR to wipe off $90 \%$ of the total $\mathrm{Pb}$ was $226 \mathrm{~h}$, which was significantly shorter compared to other tests.

A comparative study was further performed between the predicted and field-scale experimental results in order to validate the accuracy of the model. Overall, good agreements were achieved in spite of minor discrepancies caused by electric field distribution, voltage drops, ions depletion, and sediment $\mathrm{Pb}$ speciation. Neglecting of such effects was conformed to have impacts on model simulation as a $5-10 \%$ overestimation on $\mathrm{Pb}$ removals, while maintained in an acceptable range. Therefore, the designed 2D model could approximately predict the real transport-reactive processes in pilot-scale EPI-EKR.

In terms of feasibility analysis, a parametric study of EC was performed to discriminate between energy losses and energy used effectively for the optimal EPI-EKR. The total EC had an increasing trend with time and the energy expenditure caused by voltage drops and EKR system management only accounted for around 7-9\%. It was unnecessary to eliminate the sediment $\mathrm{Pb}$ since the energy utilization efficiency was significantly lower in the later stage of the remediation. This conclusion was in accordance with the cost assessment that more expenditure was required to remove the same amount of $\mathrm{Pb}$ as time passed by. Thus, the concentration of $220 \mathrm{mg} / \mathrm{kg}$ was determined as the lower limit of safety threshold for economy concern. In that way, the maximum EC cost for the treatment of $\mathrm{Pb}$-polluted sediments with EPI-EKR was $110 \$ / \mathrm{m}^{3}$ and other costs for materials expenditure, electrolyte $\mathrm{Pb}$ recycling, and labor were estimated to be around $750 \$ /$ remediation unit. Since the materials could be reused and the labor for manufacturing the EKR plant could be ignored, the total cost for the further remediation should be acceptable.

Finally, an innovative approach was applied to estimate the ecological risk induced by the recycling of $\mathrm{Pb}$-polluted sediments. In this part, the IICQ which described the quality of both soils and vegetables was calculated. The values of IICQ directly corresponded to the ecological risk level and were further classified by the relevant criterions. Light pollution was discovered in agro-ecosystem influenced by the untreated sediments. Such pollution was alleviated when decreased the sediment $\mathrm{Pb}$ content to the requested control standard $(300 \mathrm{mg} / \mathrm{kg})$. However, pollution situation of $\mathrm{Pb}$ still existed in vegetables, especially in hyperaccumulator of Brassica juncea. The agricultural environment was safe when using the sediments with $\mathrm{Pb}$ concentration of $220 \mathrm{~kg} / \mathrm{mg}$ for field plantation. This result indicated that $220 \mathrm{mg} / \mathrm{kg}$ could be 
the preferable safety threshold for cost-effective decontamination and eco-friendly recycling of $\mathrm{Pb}$-polluted sediments.

In summary, the results in the present study were important in the context of the existing literature and for the practical application of EPI-EKR as a decontamination technology. Moreover, we also believed that the modeling, experimental, and evaluating methodology developed may be applied as an useful tool for the remediation and recycling of metal-polluted sediments.

\section{Abbreviations}

EKR: electro-kinetic remediation; EPI: electrode polarity inversion; EPI-EKR: electrode polarity inversion enhanced electro-kinetic remediation; 2D: two dimensional; EC: energy consumption; CEC: cation exchange capacity; OM: organic matter; DOM: dissolved organic matter; ICP-MS: inductively coupled plasma mass spectrometry; EXP: experiment; RIE: relative impact equivalent; DDDB: deviation degree of determination concentration from the background value; DDSB: deviation degree of soil standard from the background value; QIAP: quality index of agricultural products; $\| \mathrm{CQ}_{\mathrm{S}}$ : influence index of comprehensive quality for soil; $\| C Q_{A p}$ : influence index of comprehensive quality for agricultural product; IICQ: influence index of comprehensive quality for agro-ecosystem; EXT: acid extractable fraction; OXID: oxidizable fraction; RED: reducible fraction; RES: residual fraction.
\end{abstract}

\section{Author contributions}

XM: designation of the model and pilot-scale experiments, implementation of the experiments, data analyzing and processing, and manuscript writing; XS: designation of the model; and ZZ: designation of the pilot-scale experiments. All authors read and approved the final manuscript.

\section{Author details}

${ }^{1}$ College of Agricultural Engineering, Hohai University, Nanjing 210098, China. 2 Key Laboratory of Efficient Irrigation-Drainage and Agricultural Soil-Water Environment in Southern China, Ministry of Education, Nanjing 210098, China.

\section{Acknowledgements}

The authors would like to thank Hohai University and Key Laboratory of Efficient Irrigation-Drainage and Agricultural Soil-Water Environment in Southern China for the support and assistance provided.

\section{Competing interests}

The authors declare that they have no competing interests.

\section{Availability of data and materials}

The datasets used and analyzed during the current study are available from the corresponding author on reasonable request.

\section{Consent for publication}

Not applicable.

\section{Ethics approval and consent to participate}

Not applicable.

\section{Funding}

This work was supported by the "National Natural Science Foundation of China"(51809076), the "Fundamental Research Funds for the Central Universities" (2017B1 1014), and the "China Postdoctoral Science Foundation" (2017M611677).

\section{Publisher's Note}

Springer Nature remains neutral with regard to jurisdictional claims in published maps and institutional affiliations.
Received: 7 January 2019 Accepted: 25 April 2019

Published online: 03 May 2019

\section{References}

1. Han LF, Gao B, Hao H, Zhou HD, Lu J, Sun K (2018) Lead contamination in sediments in the past 20 years: a challenge for China. Sci Total Environ 640-641:746-756

2. Xu D, Wang R, Wang WG, Ge Q, Zhang WL, Chen L, Chu FY (2019) Tracing the source of $\mathrm{Pb}$ using stable $\mathrm{Pb}$ isotope ratios in sediments of eastern Beibu Gulf, South China Sea. Mar Pollut Bull 141:127-136

3. Wang LQ, Dai LJ, Li LF, Liang T (2018) Multivariable cokriging prediction and source analysis of potentially toxic elements $(\mathrm{Cr}, \mathrm{Cu}, \mathrm{Cd}, \mathrm{Pb}$, and $\mathrm{Zn})$ in surface sediments from Dongting Lake, China. Ecol Indic 94:312-319

4. Pratte S, Bao KS, Shen J, De Vleeschouwer F, Le Roux G (2019) Centennial records of cadmium and lead in NE China lake sediments. Sci Total Environ 657:548-557

5. Kirkelund $\mathrm{GM}$, Ottosen $\mathrm{LM}$, Villumsen $\mathrm{A}(2010)$ Investigations of $\mathrm{Cu}, \mathrm{Pb}$ and $\mathrm{Zn}$ partitioning by sequential extraction in harbour sediments after electrodialytic remediation. Chemosphere 79(10):997-1002

6. Yang G, Zhang GM, Wang HC (2015) Current state of sludge production, management, treatment and disposal in China. Water Res 78:60-73

7. Akcil A, Erust C, Ozdemiroglu S, Fonti V, Beolchini F (2015) A review of approaches and techniques used in aquatic contaminated sediments: metal removal and stabilization by chemical and biotechnological processes. J Clean Prod 86(1):24-36

8. Vermeulen J, van Dijk SG, Grotenhuis JTC, Rulkens WH (2005) Quantification of physical properties of dredged sediments during physical ripening. Geoderma 129(3-4):147-166

9. Kim GN, Kim SS, Park UR, Moon JK (2015) Decontamination of soil contaminated with cesium using electrokinetic-electrodialytic method. Electrochim Acta 181:233-237

10. Li TT, Wang Y, Guo SH, Li XY, Xu YN, Wang Y (2016) Effect of polarity-reversal on electrokinetic enhanced bioremediation of Pyrene contaminated soil. Electrochim Acta 187:567-575

11. Kim BK, Baek K, Ko SH, Yang JW (2011) Research and field experiences on electrokinetic remediation in South Korea. Sep Purif Technol 79(2):116-123

12. Yuan LZ, Xu XJ, Li HY, Wang NN, Guo N, Yu HW (2016) Development of novel assisting agents for the electrokinetic remediation of heavy metalcontaminated kaolin. Electrochim Acta 218:140-148

13. Kim WS, Park GY, Kim DH, Jung HB, Ko SH, Baek K (2012) In situ field scale electrokinetic remediation of multi-metals contaminated paddy soil: influence of electrode configuration. Electrochim Acta 86(1):89-95

14. Alcántara MT, Gómez J, Pazos M, Sanromán MA (2012) Electrokinetic remediation of lead and phenanthrene polluted soils. Geoderma 173-174:128-133

15. Mao XY, Han FX, Shao XH, Arslan Z, McComb J, Chang TT, Guo K, Celik A (2016) Remediation of lead-, arsenic-, and cesium-contaminated soil using consecutive washing enhanced with electro-kinetic field. J Soil Sediment 16(10):2344-2353

16. Mao XY, Han FX, Shao XH, Guo K, McComb J, Njemanze S, Arslan Z, Zhang ZY (2016) The distribution and elevated solubility of lead, arsenic and cesium in contaminated paddy soil enhanced with the electrokinetic field. Int J Environ Sci Technol 13(7):1641-1652

17. Ait Ahmed O, Derriche Z, Kameche M, Bahmani A, Souli H, Dubujet $P$, Fleureau JM (2016) Electro-remediation of lead contaminated kaolinite: an electro-kinetic treatment. Chem Eng Process 100:37-48

18. Alshawabkeh AN (2009) Electrokinetic soil remediation: challenges and opportunities. Sep Sci Technol 44:2171-2187

19. Mao XY, Shao XY, Zhang ZY, Han FX (2018) Mechanism and optimization of enhanced electro-kinetic remediation on ${ }^{137} \mathrm{Cs}$ contaminated kaolin soils: a semi-pilot study based on experimental and modeling methodology. Electrochim Acta 284:38-51

20. Jacobs RA, Probstein RF (1996) Two-dimensional modeling of electroremediation. AlChE J 42:1685-1696 
21. Vereda-Alonso C, Miguel Rodríguez-Maroto J, García-Delgado RA, Gómez-Lahoz C, García-Herruzo F (2004) Two-dimensional model for soil electrokinetic remediation of heavy metals: application to a copper spiked kaolin. Chemosphere 54:895-903

22. Johannesson B (2010) Development of a generalized version of the Poisson-Nernst-Planck equations using the hybrid mixture theory: presentation of 2D numerical examples. Transp Porous Media 85:565-592

23. Al-Hamdan A, Reddy K (2008) Electrokinetic remediation modeling incorporating geochemical effects. J Geotech Geoenviron Eng 134:91-105

24. Paz-García JM, Johannesson B, Ottosen LM, Ribeiro AB, Rodríguez-Maroto JM (2011) Modeling of electrokinetic processes by finite element integration of the Nernst-Planck-Poisson system of equations. Sep Purif Technol 79:183-192

25. Rubio-Nieblas V, Perez-Tello M, Jacobs RA, Herrera-Urbina R (2014) Two dimensional computational modeling of the electrokinetic remediation of a copper-contaminated soil part II: sensitivity analysis for a triangular soil field. Dyna 81(183):199-207

26. Masi M, Ceccarini A, lannelli R (2017) Multispecies reactive transport modelling of electrokinetic remediation of harbour sediments. J Hazard Mater 326:187-196

27. Gomes HI, Rodríguez-Maroto JM, Ribeiro AB, Pamukcu S, Dias-Ferreira C (2015) Numerical prediction of diffusion and electric field-induced iron nanoparticle transport. Electrochim Acta 181:5-12

28. Paz-García JM, Villén-Guzmán M, García-Rubio A, Hall S, Ristinmaa M, Gómez-Lahoz C (2016) A coupled reactive-transport model for electrokinetic remediation. In: Ribeiro AB, Mateus EP, Couto N (eds) Electrokinetics across disciplines and continents. Springer International Publishing, Switzerland

29. Zoller WH, Gladney ES, Duce RA (1974) Atmospheric concentrations and sources of trace metals at the South Pole. Science 183(4121):198-200

30. Müller G (1979) Schwermetalle in den sedimenten des rheinsver nderungen seit 1971. Umschau in Wissenschaft und Technik 79(24):778-783

31. Håkanson L (1980) The quantitative impact of $\mathrm{pH}$, bioproduction and $\mathrm{Hg}$-contamination on the $\mathrm{Hg}$-content of fish (pike). Environ Pollut Ser B Chem Phys 1(4):285-304

32. Cheng JL, Zhou S, Zhu YW (2007) Assessment and mapping of environmental quality in agricultural soils of Zhejiang Province, China. J Environ Sci 19(1):50-54
33. Parkhurst $D L$, Wissmeier $L$ (2015) PhreeqcRM: a reaction module for transport simulators based on the geochemical model PHREEQC. Adv Water Resour 83:176-189

34. Masi M, Ceccarini A, lannelli R (2017) Model-based optimization of field-scale electrokinetic treatment of dredged sediments. Chem Eng J 328:87-97

35. Shackelford C, Daniel D (1991) Diffusion in saturated soil. I: background. J Geotech Eng 117:467-484

36. Fan G, Long C, Fang G, Zhou D (2014) Surfactant and oxidant enhanced electrokinetic remediation of a PCBs polluted soil. Sep Purif Technol 123:106-113

37. Qiu LW, Shen YD, Wang C (2017) pH- and KCl-induced formation of worm-like micelle viscoelastic fluids based on a simple tertiary amine surfactant. J Pet Sci Eng 162:158-165

38. Mao XY, Han FX, Shao XH, Guo K, McComb J, Arslan Z, Zhang ZY (2016) Electro-kinetic remediation coupled with phytoremediation to remove lead, arsenic and cesium from contaminated paddy soil. Ecotox Environ Safe 125:16-24

39. Pazos M, Sanromán MA, Cameselle C (2006) Improvement in electrokinetic remediation of heavy metal spiked kaolin with the polarity exchange technique. Chemosphere 62:817-822

40. Kim KJ, Kim DH, Yoo JC, Baek K (2011) Electrokinetic extraction of heavy metals from dredged marine sediment. Sep Purif Technol 7(2):164-169

41. Jansen B, Nierop KGJ, Verstraten JM (2002) Influence of pH and metal/ carbon ratios on soluble organic complexation of $\mathrm{Fe}(\mathrm{II})$, Fe(III) and $\mathrm{Al}(\mathrm{III})$ in soil solutions determined by diffusive gradients in thin films. Anal Chim Acta 454:259-270

42. Wang WH, Chen M, Guo LD, Wang WX (2017) Size partitioning and mixing behavior of trace metals and dissolved organic matter in a South China estuary. Sci Total Environ 603-604:434-444

43. Villen-Guzman M, Paz-Garcia JM, Amaya-Santos G, Rodriguez-Maroto JM, Vereda-Alonso C, Gomez-Lahoz C (2015) Effects of the buffering capacity of the soil on the mobilization of heavy metals: equilibrium and kinetics. Chemosphere 131:78-84

\section{Submit your manuscript to a SpringerOpen ${ }^{\circ}$ journal and benefit from:}

- Convenient online submission

- Rigorous peer review

- Open access: articles freely available online

- High visibility within the field

Retaining the copyright to your article

Submit your next manuscript at springeropen.com 